NBER WORKING PAPER SERIES

\title{
ISSUANCE AND INCIDENCE: SNAP BENEFIT CYCLES AND GROCERY PRICES
}

\author{
Jacob Goldin \\ Tatiana Homonoff \\ Katherine Meckel \\ Working Paper 28221 \\ http://www.nber.org/papers/w28221 \\ NATIONAL BUREAU OF ECONOMIC RESEARCH \\ 1050 Massachusetts Avenue \\ Cambridge, MA 02138 \\ December 2020
}

We gratefully acknowledge Amanda Agan, Phil Armour, Lisa Barrow, Marianne Bitler, Sarah Cohodes, Julie Cullen, Janet Currie, Stefano DellaVigna, Alex Gelber, Matt Gentzkow, Justine Hastings, Janna Johnson, Nirupama Rao, Betsey Stevenson, Jesse Shapiro, Ebonya Washington, and seminar participants at Cornell, Columbia, Duke, Williams College, George Mason, NYUWagner, UT-Austin, UCSD, UBC, University of Chicago-Booth, RAND Corporation, and NBER Summer Institute and the NBER Conference on Food Security for conversations and suggestions that have greatly improved the quality of this project. Lawrence Jin, Katherine Rittenhouse, Jason Somerville, and Vedant Vohra provided excellent research assistance. Researchers own analyses calculated (or derived) based in part on data from The Nielsen Company (US), LLC and marketing databases provided through the Nielsen Datasets at the Kilts Center for Marketing Data Center at The University of Chicago Booth School of Business. The conclusions drawn from the Nielsen data are those of the researchers and do not reflect the views of Nielsen. Nielsen is not responsible for, had no role in, and was not involved in analyzing and preparing the results reported herein. The views expressed herein are those of the authors and do not necessarily reflect the views of the National Bureau of Economic Research.

NBER working papers are circulated for discussion and comment purposes. They have not been peer-reviewed or been subject to the review by the NBER Board of Directors that accompanies official NBER publications.

(C) 2020 by Jacob Goldin, Tatiana Homonoff, and Katherine Meckel. All rights reserved. Short sections of text, not to exceed two paragraphs, may be quoted without explicit permission provided that full credit, including $\odot$ notice, is given to the source. 
Issuance and Incidence: SNAP Benefit Cycles and Grocery Prices

Jacob Goldin, Tatiana Homonoff, and Katherine Meckel

NBER Working Paper No. 28221

December 2020

JEL No. H0,H53,I38

\begin{abstract}
$\underline{\text { ABSTRACT }}$
Many safety-net programs issue benefits as monthly lump-sum payments. We investigate how the timing of Supplemental Nutrition Assistance Program (SNAP) benefit issuance affects food purchases and the incidence of the transfer. Using retail scanner data from a large sample of grocery stores and state and time variation in SNAP issuance schedules, we document large, SNAP-induced intra-month cycles in food expenditures. However, we find that retailers do not adjust prices based on these predictable patterns of demand. Our results therefore suggest that reforming issuance schedules reduce costs from SNAP-induced demand surges but are unlikely to affect the incidence of SNAP benefits.

Jacob Goldin

Stanford Law School

559 Nathan Abbott Way

Stanford, CA 94305

and NBER

jsgoldin@law.stanford.edu

Tatiana Homonoff

New York University

Robert F. Wagner School of Public Service

295 Lafayette Street, 2nd Floor

New York, NY 10012

and NBER

tatiana.homonoff@nyu.edu

Katherine Meckel

Department of Economics

Econ 210

University of California at San Diego

9500 Gilman Drive \#0508

LaJolla, CA 92093

and NBER

kmeckel@ucsd.edu
\end{abstract}




\section{Introduction}

The Supplemental Nutrition Assistance Program (SNAP) is one of the largest antipoverty programs in the United States, serving roughly 1 in 8 Americans in fiscal year 2018 (USDAFNS 2019). Participating households receive a monthly lump sum benefit that can be spent on most food products in participating grocery stores. SNAP constitutes a large share of the retail grocery market - in 2010, for example, SNAP purchases accounted for $14 \%$ of grocery sales in the United States (Wilde 2012). As such, decisions about how the program is implemented have the potential to affect a substantial share of consumers and grocery markets nationwide.

In this paper, we investigate the effects of state decisions about the timing of SNAP issuance. Previous research finds that food consumption and expenditures by SNAP recipients track monthly benefit cycles (Wilde and Ranney 2000; Shapiro 2005, Hastings and Washington 2010). Because SNAP benefits are redeemed in-kind through a larger market involving private firms and both beneficiaries and non-beneficiaries, SNAP-induced variation in aggregate customer demand can affect the purchasing power of the benefit. In particular, in states with compressed issuance schedules $]^{1}$ grocery stores face predictable, intra-month fluctuations in the nature and volume of customer demand. In response, retailers may strategically adjust food prices over the course of the month in stores where SNAP beneficiaries shop. Such pricing behavior shapes the incidence of the transfer, with the ultimate effect depending on whether retailers are induced to raise or lower their prices during the parts of the month associated with peak SNAP demand. The magnitude - and even direction - of these pricing responses are theoretically ambiguous, making it difficult to predict in advance how they shape the welfare effects of in-kind transfer programs like SNAP.

To investigate this question, we use a panel of transaction-level data that covers over 10,000 retail grocery stores in the U.S. from 2006-2014. With this data, we explore the effect

\footnotetext{
${ }^{1}$ For example, in Nevada all SNAP participants receive their benefits on the first of the month. In contrast, in Missouri, the day on which SNAP participants receive their benefits varies by person - a Missourian's issuance day may fall anywhere between the first and the $22 \mathrm{nd}$ of the month.
} 
of SNAP issuance on food expenditures and prices by leveraging differences in the share of SNAP participants that receive benefits in a given week. Specifically, we employ two main identification strategies. The first uses cross-sectional variation in SNAP issuance schedules, within and across states. The second identification strategy estimates the effect of SNAP issuance exclusively from within-state changes to the issuance schedule over time. Unlike much of the prior research on the effect of SNAP issuance timing, both of these approaches allow us to control for secular week-of-the-month effects, thus distinguishing the effect of SNAP from other regularly occurring monthly events that may influence food purchases, such as receiving a paycheck, utility bills, or the issuance of other benefits.

We first establish that SNAP issuance generates predictable intra-month fluctuations in shopper demand. Focusing initially on variation across states, we find that food sales increase $5.6 \%$ for the average grocer in a week in which all SNAP benefits are issued, compared to a week in which no benefits are issued. This effect is more pronounced in low-income areas: food sales rise $19.2 \%$ in ZIP codes in which more than $20 \%$ of households participate in SNAP. In addition, twelve states changed SNAP issuance schedules during our sample period. We find that limiting our analysis to this source of variation yields similar results: in our full sample, food sales are $6.3 \%$ higher in weeks in which all benefits are issued, compared to a week in which no benefits are issued, and 16.9\% higher in high-SNAP stores. In contrast, we find much smaller and largely statistically insignificant effects of SNAP issuance on sales of SNAP-ineligible grocery purchases.

We next investigate the relationship between the timing of SNAP issuance and withinmonth cyclicality in grocery store food prices. Notwithstanding the predictable variation in consumer demand that SNAP issuance generates, we find evidence against retailers adjusting food prices in response by an economically meaningful degree. Across specifications and samples, our point estimates are near-zero and not statistically significant. Our preferred specification yields a 95\% confidence interval that excludes average price changes larger than $0.1 \%$ in magnitude in all stores and $0.2 \%$ in high-SNAP stores. This finding is striking 
because it allows us to rule out SNAP-induced, intra-month pricing responses an order of magnitude smaller than what has been found in prior research (Hastings and Washington 2010).

Finally, we conduct a range of exploratory analyses to better understand the lack of pricing response to SNAP issuance. In particular, to shed light on how the observed fluctuations in customer demand affect grocery pricing incentives, we investigate how SNAP issuance affects within-month patterns in the aggregate price elasticity of demand faced by retailers. Instrumenting product prices with prices of the same product from same-chain stores in other markets (Hausman 1996; Nevo 2001; DellaVigna and Gentzkow 2019), we estimate the effect of SNAP issuance on within-month changes in customer demand elasticity. We find that average demand elasticity declines by approximately $1 \%$ in weeks in which all benefits are issued, suggesting that, on average, customers shopping in such weeks are slightly more price sensitive than customers shopping in other weeks of the month.

Using a simple model of grocery store behavior, we predict that these small changes in elasticity should induce only modest reductions in grocery store prices, approximately $0.1 \%$ to $0.8 \%$. Thus, perhaps surprisingly in light of the large changes in consumer behavior we observe, we do not find evidence of large incentives for retailers to adjust prices over the course of the month. In addition, although we document heterogeneity in the size of the within-month elasticity changes across individual products and chains, we observe no systematic relationship between the magnitude of these changes and the price response to SNAP issuance. We interpret these results to suggest that the effect of SNAP issuance on food prices may also be limited due to frictions that would increase the costs to grocers of making such adjustments (e.g., managerial inertia of the form explored in DellaVigna and Gentzkow (2019)).

Our paper contributes to a large literature on the incidence of redistributive transfers (Duggan and Scott Morton 2006; Rothstein 2010; Meckel 2020; Handbury and Moshary 2020). Our setting highlights a potentially important but under-explored mechanism through 
which institutional design can shape the incidence of a redistributive program; namely, when the benefit is provided in-kind through a private market and where the timing of issuance generates regular and predictable variation in the nature of demand $4^{2}$ Prior research in the SNAP context suggests the timing of issuance may affect the purchasing power of the benefits; using data from three grocery stores from one chain located in a single state, Hastings and Washington (2010) find that food prices were approximately $3 \%$ higher in the first week of the month (when the state issued its SNAP benefits) than at the end of the month (when SNAP expenditures were relatively low). We build on this analysis by using a dataset with broad national coverage to dramatically expand the number of stores and retail chains considered. In so doing, we increase the likelihood that our results reflect the national grocery store market, rather than the pricing decisions of a single retailer.

Our second contribution is primarily methodological. A number of influential papers study the effects of SNAP issuance on the timing of food purchases (Wilde and Ranney 2000; Shapiro 2005; Hastings and Washington 2010; Castner and Henke 2011; Todd 2015) and other related outcomes (Seligman et al. 2014; Gennetian et al. 2016; Gregory and Smith 2019). Because the vast majority of such studies identify the effect of SNAP issuance from intra-month patterns in behavior, they risk conflating the effects of SNAP issuance with other regularly occurring monthly events that also affect behavior such as timing of rent payments or other bills, paycheck receipt (Stephens Jr. 2006), or receipt of other monthly benefit programs such as TANF or Social Security (Stephens Jr. 2003; Mastrobuoni and Weinberg 2009) $!^{3}$ In contrast, by exploiting variation in issuance schedules within and across

\footnotetext{
${ }^{2}$ For example, Social Security or TANF issuance policies are likely to affect the timing of the benefit use; however, since these benefits are cash instead of in-kind, we may not expect to see a price response by a specific retail industry. In contrast, changes to Medicare Part D may induce price responses by prescription drug providers, but the irregular timing of these benefits is unlikely to affect the use of these benefits.

${ }^{3}$ Some prior research investigating the cyclicality of SNAP benefit use, including Todd (2015), Smith et al. (2016), Hamrick and Andrews (2016), and Castellari et al. (2017), partially address this concern by including in their sample multiple states that vary in their SNAP issuance schedules. Bias may persist in such designs, however, because in all states SNAP issuance dates tend to be concentrated in the earlier part of the calendar month (Appendix Table A.1). An important exception is Shapiro (2005), which uses states that vary in their issuance dates while also controlling for calendar day fixed effects. Finally, Beatty et al. (2019) directly study interactions between SNAP issuance and two of the possible confounding factors, paycheck receipt and the issuance of other social insurance benefits, by comparing SNAP cyclicality across
} 
states, our identification strategy allows us to control for monthly patterns in individuals' behavior that are unrelated to SNAP issuance 4 Similarly, this innovation allows us to more confidently attribute retailer pricing responses to SNAP issuance rather than other "first of the month" effects that have been the focus of prior work (Hastings and Washington 2010) $!^{5}$

More generally, our paper also contributes to a growing literature on grocery pricing strategies. For example, DellaVigna and Gentzkow (2019) document uniform pricing of products across grocery stores belonging to the same chain, despite wide variation in customer demographics and degree of market competition. By contrast, other recent work finds that retailer pricing responds to local demand conditions (Stroebel and Vavra 2019). Rather than focusing on differences in price-setting across stores, our focus is on variation within a single store over time, for which the constraints on price-setting may operate differently. Our finding that retailers do not adjust prices in response to predictable variation in demand caused SNAP issuance is similar to that of DellaVigna and Gentzkow (2019); however, an important difference is that such price responses appear less likely to be optimal in our setting - even absent managerial decision costs or other frictions. Our analysis is also related to the literature that studies grocer responses to seasonal demand fluctuations. For example, Chevalier, Kashyap, and Rossi (2003) finds that grocers compete to capture seasonal demand shocks by offering a high-demand product (e.g., turkey on Thanksgiving) below cost. Although this finding might suggest that retailers would lower food prices following SNAP issuance to get SNAP beneficiaries "in the door," we find no evidence supporting this hypothesis.

Finally, we contribute to broader literature that studies the effects of SNAP policy on prices. This literature investigates how the size and generosity of the SNAP program affects food prices as well as the effects of other state and federal policy changes in program enrollindividuals likely to be affected in different ways by these non-SNAP monthly income cycles.

${ }^{4}$ Apart from the difference in outcomes we focus on (retailer-level sales and prices versus caloric intake and individual expenditures), this aspect of our identification strategy builds on Shapiro (2005) by avoiding potential biases from correlations between state issuance schedules and within-month purchasing patterns.

${ }^{5}$ Notably, an earlier working paper version of Hastings and Washington (2010) includes an additional four stores from the same retailer located in states that stagger benefit issuance across the first 10 days of the month and finds that prices decline beginning in the third week of the month, consistent with the issuance schedule driving the change in behavior (Hastings and Washington 2008). 
ment rules (Jaravel 2018; Makioka 2018; Leung and Seo 2019). Whereas these papers study the effect of SNAP on average food prices during some interval of time, our focus is on how SNAP shapes short-term price fluctuations around that average over the course of a month. Because both of these channels shape the food prices faced by SNAP recipients and hence the real purchasing power of the SNAP benefits, both are relevant for understanding the incidence of the program.

The paper is structured as follows. Section 2 describes the institutional background. Section 3 describes our data and the construction of the variables used in the analysis. Section 4 presents our results related to food sales. Section 5 presents our results related to food prices. Section 6 explores potential explanations for the observed retailer pricing response. Section 7 concludes.

\section{Institutional Background}

SNAP served roughly 40 million individuals in an average month of fiscal year 2018 with a federal budget for that year of $\$ 65$ billion (USDA-FNS 2019). SNAP purchases comprise a sizable share of the retail grocery market. Wilde (2012) estimates that 10-15\% of food sales were purchased through SNAP and Wal-Mart estimates $4 \%$ of its total sales revenue comes from the SNAP program (Clark 2020).

Eligibility for SNAP varies by state but federal law requires participating households to have gross monthly income below $130 \%$ of the Federal Poverty Line $(\$ 2,183$ per month for a family of four in 2020). A number of states also limit eligibility based on the value of a household's assets (for details, see Center on Budget and Policy Priorities (2018)).

SNAP benefits are issued via debit-like Electronic Benefit Transfer (EBT) cards that can be used to purchase most food products at participating grocery stores. Omitted foods include "ready to eat" prepared foods, alcohol and tobacco products, and vitamins (U.S. Department of Agriculture 2013). Once per month, SNAP benefits are issued to participating households in a lump-sum payment. When a household's benefits are issued, their EBT card 
is automatically reloaded and any remaining balance is carried over from prior months. SNAP customers proceed through the standard checkout line and tender their purchases with their EBT card, as well as other payment methods if expenditures exceed their card balance or if purchasing ineligible products.

In some states, each participating household receives its benefits on the same day as every other participating household. States that issue all SNAP benefits on a single day mostly do so on the first of the month. In contrast, other states stagger benefit issuance over multiple days - for example, some households may receive their monthly benefits on the first, some on the third, and some on the fifth day of the month. Among states that stagger benefit issuance, there exists considerable variation in the number of days on which benefits are issued. For example, Wyoming staggers its benefit issuance across the first four days of the month, whereas Missouri issues benefits between the first and 22nd days of the month.

Appendix Table A.1 details issuance policies by state. At the start of our sample period (in 2006), 14 states issued benefits during the first calendar week only, 2 states issued benefits during the second calendar week only, 24 states issued benefits on days spanning the first two calendar weeks, and 9 issued benefits on days spanning three or more calendar weeks ${ }^{6}$ During the course of the years we study, 12 states expanded the number of days during the month on which they issue benefits. In 2014, 17 states in our sample staggered issuance across three or more calendar weeks.

\section{Data}

Our primary data source is the Kilts-Nielsen Retail Scanner data set, a large panel of weekly retail transaction records. The data contain point-of-sale records at the store and product level from the 48 contiguous states and the District of Columbia between 2006 and 2014 . We focus our analysis on data from the 11,508 grocery stores in the sample. The stores included in our sample account for approximately $53 \%$ of all grocery store sales volume in

\footnotetext{
${ }^{6}$ We use "calendar week" to refer to the specified week number in a given month. For example, the first calendar week refers to days 1-7 of the month.
} 
the geographic markets covered by Nielsen.7

Each observation includes sales volume and volume-weighted average price for each store, week, and Universal Product Code (UPC, or product). The weekly product price is averaged across all units sold in a store. The price we observe incorporates retailer discounts and specials, such as coupons or loyalty card price reductions, but does not reflect discounts from manufacturer coupons (e.g., a manufacturer rebate).

The majority of the weekly data that stores report to Nielsen corresponds to the week that begins on a Sunday and ends the following Saturday $\left.\right|^{8}$ We transform the raw Nielsen data to represent the first four calendar weeks of each month. To do so, for each calendar week, we compute the average price of each product across the (one or two) Sunday-toSaturday weeks in which the observed store-week falls, weighting by the number of dates in the calendar week that fall in each respective Sunday-to-Saturday week $\bigsqcup^{9}$ We discard any data associated with calendar days 29 to 31 .

We impose two additional product-level restrictions on our data. First, Nielsen does not report a product price for store-weeks in which a product was not sold in a given store. To limit the influence on our results of changes in the composition of products for which we observe price, we restrict our analysis to store-month-products for which we observe price in all four weeks 10 Second, because our focus is on SNAP-induced changes in demand, in our main analyses we exclude products sold by grocery stores for which SNAP benefits cannot be used (e.g., non-food items or prepared foods). ${ }^{11}$

\footnotetext{
${ }^{7}$ In restricting our analysis to grocery stores, we exclude drug stores as well as "superstores" that retail a more general line of goods, such as Target.

${ }^{8}$ Although all stores report price and volume data for a seven-day period, this period need not end on a Saturday; for example, stores may submit data that aligns with their promotion week instead. Rather than including the exact dates used by each retailer, Nielsen assigns the data to the "best fit Saturday," that is, the Saturday that most closely matches the promotion week. Because no information is provided on the actual date range for the weekly data by retailer, we use the date provided.

${ }^{9}$ To illustrate, consider a month in which the 1st day of the month is a Saturday. For the week that includes the 1st of the month, Nielsen reports a price of $\$ 1$, and for the following week (the 2nd through the 8th), Nielsen reports a price of $\$ 2$. We would calculate the price of this product in the first calendar week of the month as $\$ 1.00 \frac{1}{7}+\$ 2.00 \frac{6}{7} \approx \$ 1.86$.

${ }^{10}$ Thus, the composition of products for a given store may vary across months but not within a single month.

${ }^{11}$ We consider the effect of SNAP issuance on purchases and prices for SNAP-ineligible products in Section
} 
We supplement the Retail Scanner Data using a second Kilts-Nielsen data set, the Consumer Panel. This data set consists of daily, product-level expenditure data for a panel of 40,000 to 60,000 households per year from 2004 to 2014. Participants use in-home optical scanners to record their purchases. We incorporate data from the Consumer Panel in two main ways. First, a number of our analyses rely on data about SNAP prevalence in the neighborhood in which the store is located. Although the Retail Scanner Data include state and county identifiers for each store, they do not include location information at a finer level of geography. To estimate local SNAP prevalence, we use the following method, similar to DellaVigna and Gentzkow (2019). For a given store, we calculate total expenditures per ZIP code, for each ZIP code of residence of its shoppers in the Consumer Panel. We then assign the store the average SNAP prevalence of its shoppers' ZIP codes, weighting by the number of shopping trips to the store by customers in a given ZIP code. We restrict our analysis to the $97 \%$ of stores in the Retail Scanner Data for which this method yields a ZIP code. We use the store's ZIP code to link our data with ZIP code-level demographic data from the 5-year American Community Survey spanning 2008-2012 (Census Bureau 2012). In particular, we use the share of households that participate in SNAP from these data.

Second, we construct an index to reflect the average price faced by SNAP customers in a given store and week. To do so, we first create expenditure shares by product for SNAPeligible households from the Consumer Panel ${ }^{12}$ We construct these expenditure shares for each SNAP-eligible product by summing expenditures for the product across households and dates during our sample period, and then scaling that sum by total expenditures on all SNAP-eligible products over the same time period. By construction, these expenditure shares are constant over time. We denote the expenditure share for product $k$ as $\omega_{k}$. We 4.

\footnotetext{
${ }^{12}$ We impute SNAP eligibility from household income and family size by applying the federal gross income test. Household income is reported with a two-year lag in the Consumer Panel (i.e., households are asked about their income two years before the panel year); therefore, we reassign households to their income reported two years in the future. Doing so excludes households that do not participate for two consecutive years after the year in which their shopping is reported. We cannot apply the SNAP asset test because the Consumer Panel does not report data on household assets.
} 
normalize the expenditure shares to sum to one in a given store-month, and denote the normalized expenditure shares by $\widetilde{\omega}_{k s m y}$ for store $s$, calendar month $m$, and year $y$.

Following Hastings and Washington (2010), we next use the expenditure shares to construct an expenditure-weighted index of log prices for each store-week using the following equation:

$$
\log \left(P_{\text {swmy }}\right)=\sum_{k} \widetilde{\omega}_{k s m y} \log \left(p_{k s w m y}\right)
$$

where $p_{\text {kswmy }}$ denotes the unit price for product $k$ sold in store $s$ in calendar week $w$, calendar month $m$, and year $y$.

We similarly construct an index of expenditures on SNAP-eligible products in a given store and week. The expenditure index is defined as the log of weighted expenditures in the store-week, where the weights (i.e., the expenditure shares) are the same as those used to construct the price index:

$$
\log \left(Y_{\text {swmy }}\right)=\sum_{k} \widetilde{\omega}_{k s m y} \log \left(y_{k s w m y}\right)
$$

where $y_{\text {kswmy }}$ denotes expenditures on product $k$ in store $s$ in calendar week $w$, calendar month $m$, and year $y$. As with the price index, the expenditure index attaches higher weight to products that are more likely to be purchased by SNAP-eligible households, and for which we would therefore be more likely to observe SNAP-induced changes in demand or prices ${ }^{13}$

In many of our analyses, the main explanatory variable of interest is the share of SNAP benefits a state issues in a given calendar week, Issuance swmy $^{14}$ To illustrate, if store $s$ is located in a state that distributes all benefits on the 1st of the month, sssuance $_{\text {simy }}=1$

\footnotetext{
${ }^{13}$ As robustness checks, we consider unweighted analyses and analyses that focus on an alternative subset of products.

${ }^{14}$ We allow issuance policy to vary at the county-level when applicable and subject to data availability. Specifically, Pennsylvania and Ohio allow issuance policy to vary at the county-level and New York City follows a different issuance schedule than the rest of New York; however, in the case of Ohio, we do not have data on the $15 \%$ of counties that do not stagger, so we assume that all counties in the state follow the same schedule.
} 
and Issuance $_{\text {swmy }}=0$ for $w \in\{2,3,4\}$. Alternatively, if the state distributes its benefits

evenly from the 1 st through the 15 th of the month, Issuance swmy $=\frac{7}{15}$ for $w \in\{1,2\}$, Issuance $_{\text {swmy }}=\frac{1}{15}$ for $w=3$, and Issuance $_{\text {swmy }}=0$ for $w=4$

\section{SNAP Issuance and Food Expenditure Cyclicality}

Our goal in this section is to isolate the causal effect of SNAP issuance on intra-month patterns in grocery expenditures. Columns 1-3 of Table 1 estimate variants of the following model:

$$
\log Y_{\text {swmy }}=\beta \text { Issuance }_{\text {swmy }}+\alpha_{\text {smy }}+\delta_{w m y}+\gamma X_{s y} \zeta_{w}+\varepsilon_{\text {swmy }}
$$

where $\alpha_{s m y}$ denotes store-month-year fixed effects, $\delta_{w m y}$ denotes year-month-week fixed effects, $\zeta_{w}$ denotes calendar week fixed effects, and $X_{\text {swmy }}$ is a vector of time-varying characteristics of the state in which store $s$ is located. As described above, Issuance $_{\text {swmy }}$, denotes the share of SNAP benefits issued in calendar week $w$ of month $m$ of year $y$ in the state in which store $s$ is located. Hence, $\beta$ represents the percent increase in expenditures for weeks in which 100 percent of SNAP benefits are issued relative to weeks in which no benefits are issued. Each observation is weighted at the store-level by average annual food sales.

As a benchmark, Column 1 of Table 1 reports the estimated effect of SNAP issuance from a regression that controls only for store-month-year fixed effects. The effect of SNAP issuance is identified from comparing expenditures across weeks in a given store, based on differences in the share of SNAP benefits issued in the specified weeks. Note that because this specification includes state-month-year fixed effects, it isolates within-month variation in food expenditures from state changes to SNAP policy that affect benefit generosity or

\footnotetext{
${ }^{15}$ Twelve states in our sample assign a case's issuance date based on the first letter of their last name, which may result in an uneven distribution across benefit issuance days, biasing our measure Issuance swmy $_{\text {. }}$ We do not have data on the distribution of last names by state, however, in robustness checks below, we test the sensitivity of our results to exclusion of states with this issuance assignment method as well as a re-weighting of Issuance $_{\text {swmy }}$ by nationwide name distributions. Relatedly, Illinois' policy assigns issuance date based on a combination of the case name and the type of case. We obtain administrative data from Illinois on the number of cases issued benefits by day and adjust our measure of Issuance $_{\text {swmy }}$ to match this distribution.
} 
other features of program administration of the type studied in Ganong and Liebman (2018) and Jaravel (2018), The results imply that expenditures are 5.1\% higher in weeks in which all benefits are issued compared to weeks in which no benefits are issued.

As with much of the prior literature, the effect reported in Column 1 risks conflating the effect of SNAP issuance with other sources of intra-month cyclicality in consumption, such as the timing of paychecks, utility bills, or the issuance of other benefits. To address this concern, Column 2 replicates Column 1 but additionally controls for year-month-week fixed effects. In doing so, it absorbs within-month cyclicality that is unrelated to SNAP issuance. Figure 1 (Panel A) graphically presents the variation underlying this specification; after partialling out the store-month-year and year-month-week fixed effects, the relationship between SNAP issuance and log expenditures appears fairly linear and remains upward-sloping. Indeed the estimated effect reported in Column 2 is quite similar to that in Column 1 (expenditures are $5.6 \%$ higher in weeks in which all benefits are issued relative to weeks in which no benefits are issued), suggesting that non-SNAP sources of within-month cyclicality are unlikely to have driven the findings of prior analyses of SNAP-induced consumption that failed to account for such factors.

The specification in Column 2 identifies the effect of SNAP issuance from cross-sectional variation across states in issuance policies, and, to a lesser extent, by changes in a state's issuance policy over time. However, it is possible that either of these sources of variation could be correlated with other factors that affect expenditure cyclicality. For example, larger states might tend to exhibit more within-month cyclicality (for reasons unrelated to SNAP) and also to stagger benefit issuance over a larger number of days. To address some of these possibilities, Column 3 (our preferred specification, matching equation (3)) controls for the calendar week interacted with state population, gross domestic product, and unemployment rate. Again, the results are virtually unchanged by these additions.

Because our expenditure data is at the retailer level, it reflects the shopping behavior of both SNAP recipients as well as other shoppers. Hence, to the extent our results are driven 
by SNAP-induced cyclicality, we would expect them to be more pronounced in stores that are located in neighborhoods with high SNAP prevalence. Figure 2 explores this possibility by displaying the estimated effect of SNAP issuance by local SNAP prevalence, using the specification reported in Column 3 of Table 1. In ZIP codes in which fewer than $5 \%$ of households participate in SNAP, there is a small amount of cyclicality: expenditures are 1.8\% higher in weeks in which 100 percent of SNAP benefits are issued relative to weeks with no issuance. By comparison, this estimate grows monotonically with local SNAP prevalence, increasing to $49 \%$ for stores located in ZIP codes in which over $35 \%$ of households receive SNAP 16

Along similar lines, Panel B of Table 1 restricts the analysis to stores in ZIP codes for which we estimate that greater than $20 \%$ of the population receives SNAP ${ }^{17}$ As suggested by Figure 2, the estimated effects of SNAP issuance for such high-SNAP stores are substantially higher than those of the overall sample. In our preferred specification, expenditures in highSNAP stores are $19.3 \%$ higher in weeks in which all benefits are issued relative to weeks in which no benefits are issued.

In Columns 2 and 3, identification of the effect of the SNAP issuance schedule comes from variation across states in issuance policy as well as within-state issuance policy changes over time. However, cross-sectional policy variation between stores may be correlated with other factors that shape a store's cyclicality, unrelated to SNAP issuance. To address this possibility, we next turn from specifications that rely on cross-sectional variation across states in issuance policies to specifications that exclusively exploit within-state changes in policy over time. In particular, Columns 4 and 5 of Table 1 estimate variants of the following model:

$$
\log Y_{\text {swmy }}=\beta \text { Issuance }_{\text {swmy }}+\alpha_{\text {smy }}+\delta_{w m y}+\gamma X_{s y} \zeta_{w}+\phi_{s w}+\varepsilon_{\text {swmy }}
$$

\footnotetext{
${ }^{16}$ Appendix Figure A.1 shows a similar relationship between SNAP-induced cyclicality and SNAP prevalence at the level of the grocery chain.

${ }^{17}$ In principle, SNAP participation at a given store may differ from the general population in a neighborhood. However, using the Consumer Panel, we estimate that the share of customers in the stores in this "high-SNAP" sample of neighborhoods that are SNAP-eligible is also approximately $20 \%$.
} 
where $\phi_{s w}$ denotes store by calendar week fixed effects. Including these fixed effects implements a difference-in-differences analysis, in which identification comes from within-state policy changes over time. A benefit of this approach is that it avoids the identification threats described above; a downside is that with only 12 policy changes during our sample period (largely concentrated during the final three years), the effect it identifies is not nationally representative and will be less precisely estimated.

The difference-in-differences analysis requires that, absent the policy changes, intramonth cyclicality would have evolved similarly in states that did and did not modify their benefit issuance schedules. This assumption may be violated, for example, if state-level trends in expenditure cyclicality prompt lawmakers to adjust the issuance schedules to relieve congestion at grocery stores 18 To assess the plausibility of this parallel trends assumption, Figure 3 presents an event-study analysis of the effect of the policy changes on the cyclicality of within-month consumption, which we measure as the share of monthly purchases made in the first two weeks ${ }^{19}$ The figure suggests the reforms reduced intra-month cyclicality in expenditures, especially within the high-SNAP stores most affected by the reforms. In contrast, the figure provides no evidence of differential trends in cyclicality in the period leading up to the reforms, consistent with the parallel trends assumption underlying the difference-in-differences analysis.

Column 4 of Table 1 presents results from a difference-in-differences analysis, adding store by calendar week fixed effects to the specification reported in Column 2. The point estimate increases slightly (to 6.4\%) relative to the specifications identified from cross-sectional variation in state policy, and the standard error of the estimate doubles in size ${ }^{20}$ Finally, to

\footnotetext{
${ }^{18}$ For example, both the USDA and grocery store lobbying groups have recommended that states stagger SNAP issuance for this reason (Cloud 2012).

${ }^{19}$ Ten out of the 12 policy changes in our data expand the share of benefits issued in weeks 3 and 4 relative to weeks 1 and 2. The two exceptions are Oklahoma and Virginia, which we exclude from this analysis.

${ }^{20} \mathrm{~A}$ potential concern with this analysis is that, because states reform their SNAP issuance schedules at different times, the parallel trends assumption may be violated when the effects of the SNAP issuance reforms vary over time (Goodman-Bacon 2018). To investigate the robustness of our analysis to this issue, Appendix Table A.2 separately estimates the effect of SNAP issuance for each state policy reform, using as controls only those states that did not revise their issuance schedule during our sample period. Although there is substantial variation in the magnitude of the individual estimates for each state, the overall story is
} 
address the possibility that the effects of the policy changes may be confounded by other state-level trends that would affect within-month expenditure cyclicality, Column 5 adds controls for the time-varying state characteristics that were included in Column 3. The results are similar to those in Column 4. Columns 4 and 5 in Panel B again show much larger effects when the analysis is restricted to the sub-sample of high-SNAP stores.

We next consider a range of robustness checks on the main cross-sectional and differencein-differences results (Columns 3 and 5 of Table 1). Columns 1 and 2 of Appendix Table A.3 present versions of these analyses that are not weighted by store volume. Similarly, Columns 3 and 4 present results for total food expenditures, rather than our main outcome measure, which aggregates expenditures using weights based on the purchases of SNAPeligible shoppers. These alternative specifications yield qualitatively similar results to our main analysis.

We estimate two robustness checks motivated by potential measurement error in our main explanatory variable reflecting the timing of SNAP issuance. Although most states issue benefits uniformly across issuance days (e.g., based on the last digit of the recipient's Social Security Number or case number), 10 states allocate benefit issuance across days based on first letter of the recipient's last name. To account for non-uniform issuance of benefits across recipients in such states, Columns 5 and 6 of Appendix Table A.3 construct the issuance share variable by combining the issuance schedule for such states along with the national distribution of last names from the 2010 Census ${ }^{21}$ As an alternative check, Columns 7 and 8 exclude these states along with three others that issue benefits non-uniformly across issuance days. ${ }^{22}$ In both cases, the results are similar to those we obtain when using our full sample or main measure of SNAP issuance share.

Thus far we have parameterized variation in issuance policy through the share of benefits

consistent with the results of our main specification; the average of the state-specific estimates (weighted by the volume of sales in the stores in each state) is $4.4 \%$ for all stores and $12.8 \%$ for high-SNAP stores.

${ }^{21}$ This re-weighting is not possible for two states, Maryland and Missouri, which employ more elaborate distribution schedules.

${ }^{22}$ The additional excluded states are Louisiana, Ohio, and South Carolina. 
issued in a given calendar week. Appendix Table A.4 explores within-month cyclicality within broader categories of state issuance policy. We estimate separate regressions for states with four different SNAP issuance policies: (1) all benefits issued during the first week of the month; (2) all benefits issued during the second week of the month; (3) all benefits issued during the first and second weeks of the month; and (4) benefits issued during the first three or more weeks of the month. Each of these regressions take the form:

$$
\log Y_{\text {swmy }}=\alpha+\sum_{w=2}^{4} \zeta_{w}+\delta_{s m y}+\varepsilon_{\text {swmy }}
$$

The estimated $\zeta_{w}$ terms measures the change in food expenditure within a store between the first week of the calendar month (the omitted category) and the $w$ th week of the calendar month ${ }^{23}$ The results suggest that within-month expenditure patterns closely track SNAP issuance schedules; for example, in high-SNAP stores located in states that issue all benefits in week 1 , food expenditures in that week are between 15 and 21 percent higher than in other weeks of the month. In contrast, we observe little evidence of cyclicality in states that spread issuance across three or four weeks.

Finally, we have so far focused on the effect of SNAP issuance on the timing of SNAPeligible purchases. It is also possible that SNAP issuance affects expenditures on food or nonfood products that cannot be paid for with SNAP benefits. For example, if benefit issuance induces more SNAP-enrolled customers to shop in a given week, those customers may also purchase more SNAP-ineligible products during those weeks while at the grocery store. To explore this possibility, Appendix Table A.5 investigates the effect of SNAP issuance on nonfood grocery items and alcohol purchases. We observe no evidence that SNAP issuance affects the timing of alcohol purchases and some evidence for a small effect on non-food grocery items in high-SNAP stores, although the latter is not consistent across specifications.

\footnotetext{
${ }^{23}$ To the extent that the timing of SNAP issuance affects purchases in weeks other than the week of issuance, these effects may be reflected in the $\zeta_{w}$ terms.
} 


\section{SNAP Issuance and Retail Prices}

The previous section provides evidence that SNAP issuance causes retailers to face predictable monthly fluctuations in customer shopping behavior, especially in states with compressed benefit issuance schedules and in locations where SNAP participation is high. In response to these fluctuations in demand, retailers may strategically vary prices over the course of the month to maximize profits. Alternatively, to the extent retailer prices do exhibit SNAP-induced pricing cyclicality, it could be that this cyclicality is what induces the observed fluctuations in consumer demand. This section empirically investigates these possibilities by studying the effect of SNAP issuance on retailer prices.

Using the price index described in Equation (1), we estimate a similar set of specifications as those reported in Table 1 to estimate the effect of SNAP issuance on retail prices. Column 1 of Table 2 estimates the relationship between SNAP issuance and log prices, controlling for store-month-year fixed effects. The result implies that prices are approximately $0.13 \%$ lower in weeks in which all benefits are issued compared to weeks in which no benefits are issued. However, adding year-month-week fixed effects (Column 2) to this analysis causes the point estimate to switch signs and decline in magnitude to $0.04 \%$, suggesting that the difference in prices may have been due to within-month fluctuations unrelated to SNAP issuance. We present visual evidence for this result in Figure 4. Adding controls for state characteristics (Column 3, our preferred specification) yields similar evidence against withinmonth price fluctuations. The estimated $95 \%$ confidence interval for the effect of SNAP issuance excludes price changes greater in magnitude than $0.1 \%$. Finally, the difference-indifferences analyses, reported in Column 4 and 5, yield slightly larger, but still near-zero and statistically insignificant, estimates of the effect of SNAP issuance on retailer prices ${ }^{24}$ By comparison, Hastings and Washington (2010) estimate that prices increase by between $2.5 \%$

\footnotetext{
${ }^{24}$ Appendix Figure A.2 replicates the event-study analysis in Figure 3 for the effect of the SNAP issuance policy changes on prices, and provides no evidence of differential pre-trends based on whether a state changed policies. In addition, Appendix Table A.6 replicates the state-specific analyses contained in Appendix Table A.2 for prices instead of expenditures; the average of the state specific estimates (weighted by the volume of sales in the stores in each state) is $-0.18 \%$ for all stores and $0.02 \%$ for high-SNAP stores.
} 
and $3.1 \%$ in the first week of the month, depending on their specification; these effects are approximately 20 times larger than our largest estimated effect across specifications.25

We next investigate whether the observed null effects on prices mask SNAP-induced price fluctuations in stores located in high-SNAP neighborhoods. Panel B of Table 2 replicates the prior analysis for stores located in ZIP codes in which at least $20 \%$ of residents participate in SNAP. The analyses yield estimated effects of SNAP issuance on prices that are slightly larger than those reported in Panel A, but still near-zero and not statistically significant. The 95\% confidence interval excludes price effects greater in magnitude than $0.2 \%$. Figure 5 further investigates the relationship between SNAP-induced price fluctuations and neighborhood SNAP prevalence. As with Table 2, the figure reveals a slightly larger price response in higher-SNAP stores, although, even in such stores, the magnitude of the observed effects are small and statistically indistinguishable from zero ${ }^{26}$

A different concern is that our price index - which creates one weekly price per store weighted by purchases of SNAP-eligible households - may mask differences in price response by product. For example, retailers may only strategically price products that are in high demand among SNAP recipients or products that see the highest SNAP-induced intra-month cyclicality in demand. To shed light on this possibility, we replicate our results separately for the top 10 product groups (e.g., "cheese," "bread") by expenditure share among SNAPeligible customers during our sample period ${ }^{27}$ Whereas we observe that SNAP-induced cycli-

\footnotetext{
${ }^{25}$ Notably, Hastings and Washington (2010) restricted their focus to stores with particularly high shares of SNAP shoppers (14 to 45 percent of sales), meaning that our overall results are not directly comparable to theirs. As shown in Figure 5 and Panel B of Table2 2 however, we find no evidence for price cyclicality even in stores for which we estimate a high share of SNAP shoppers. A potential limitation of our analysis relative to Hastings and Washington (2010) is that we do not directly observe individual-level SNAP participation, so it is possible that these neighborhood-based estimates overstate the true SNAP share in a store's customer base. That being said, the magnitude of SNAP-induced sales cyclicality we estimate is comparable to that observed in Hastings and Washington (2010), suggesting that measurement error in SNAP participation is not driving the difference between the two sets of results. In addition, as described above, we estimate that approximately $20 \%$ of customers in the stores located in our high-SNAP neighborhoods are SNAP participants, which, assuming a roughly $80 \%$ household take-up rate during the years of our sample period (Leftin, Eslami, and Strayer 2011, Gray and Cunnyngham 2016), suggests that these stores tend to face SNAP customer bases within the range of stores studied by Hastings and Washington (2010).

${ }^{26}$ In contrast, Appendix Figure A.3 shows a negative relationship between SNAP-induced price cyclicality and SNAP prevalence at the the grocery chain level, although here too the result is not statistically significant.

${ }^{27}$ Together, these product groups cover $47 \%$ of SNAP-eligible household food spending.
} 
cality in sales varies greatly across product groups (Appendix Table A.7), the estimated price effects are close to zero and, for the most part, not statistically significant (Appendix Table A.8). Alternatively, retailers might limit their price responses to products that are the most disproportionately purchased by SNAP recipients compared to non-recipients. To investigate this possibility, Appendix Table A.9 restricts our analysis to the 10 product modules with the highest estimated ratio of expenditures by SNAP-eligible customers relative to non-eligible customers. Here too, the results are similar as with our overall product sample.

We next consider a range of robustness checks, similar to those presented in the prior section. In particular, Appendix Table A.10 shows the results are not sensitive to unweighted analyses (Columns 1 and 2), constructing the SNAP issuance variable to account for state issuance schedules based on last names (Columns 3 and 4), or excluding states that issue benefits non-uniformly across issuance dates (Columns 5 and 6).

In addition, Appendix Table A.11 investigates the possibility that the lack of pricing results are driven by the absence of price data for products not purchased during a storeweek ${ }^{28}$ To assess the importance of this feature of our data, we replicate our expenditure and price analyses for the subset of stores for which at least $80 \%$ (Columns 1-4) and at least $90 \%$ (Columns 5-8) of expenditures are preserved, respectively. Although restricting the sample in this way yields slightly larger expenditure cyclicality, we observe no consistent evidence that this restriction is attenuating our price results.

Along similar lines, we next examine the role that coupon usage could play in driving our pricing results. Recall that the prices we observe in our retailer data are net of certain coupons and loyalty discounts. Hence, if SNAP customers are more likely to shop in weeks that SNAP benefits are issued, and if SNAP customers are also more likely to apply such coupons or discounts to their purchases, the prices we observe may vary based on SNAP issuance even

\footnotetext{
${ }^{28}$ Recall that we exclude products in store-months for which the product was not purchased in one or more weeks (approximately 17\% of total food expenditures during our sample period). This sample restriction might distort our results if stores increase prices of certain products during SNAP issuance weeks, and those higher prices prevent customers from purchasing those products - rendering the price increases unobservable to us.
} 
when retailers do not change them. Or, conversely, this phenomenon could cause us to observe no change in prices following benefit issuance even if stores tend to increase prices in such weeks. To investigate these possibilities, Appendix Table A.12 explores the effect of SNAP issuance on the use of coupons (Columns 1 and 2) and the purchase of discounted items (Columns 3 and 4) using the Consumer Panel data set. We find no evidence that the use of coupons or receipt of product discounts vary with the SNAP issuance schedule.

Finally, Appendix Table A.13 considers the effect of SNAP issuance on the prices of the two categories of non-SNAP eligible grocery store products considered in the prior section: non-food grocery items and alcohol. We observe small but statistically significant effects of issuance on non-food grocery items, although the effects disappear for stores located in high-SNAP neighborhoods. We observe no consistent evidence of SNAP issuance affecting alcohol prices.

\section{Understanding the Lack of Price Response to SNAP Issuance}

The results thus far provide evidence that consumers substantially increase food expenditures in weeks that SNAP benefits are issued but that retailers do not adjust food prices in those weeks by more than a very modest degree (if at all). In this section, we conduct several exploratory analyses to better understand these patterns.

As an initial step, we focus on one input into retailers' price setting decisions - withinmonth variation in the aggregate price elasticity of demand that retailers face. SNAP issuance may affect these elasticities through several channels. For example, the type of customers who shop following SNAP issuance may have higher or lower elasticities than customers who shop during other weeks in the month. In addition, households may exhibit different price sensitivities when spending SNAP benefits than when using cash either because of mental accounting (Hastings and Shapiro 2018) or a fixed cost of traveling to a store.

To estimate how SNAP issuance affects demand price elasticities, we estimate the following product-level econometric model: 


$$
\begin{aligned}
\log q_{k s w m y}=\eta \text { Issuance }_{\text {swmy }} \log P_{\text {sswmy }}+\beta \text { Issuance }_{\text {swmy }}+\mu \log P_{k s w m y} \\
\\
+\alpha_{k s m y}+\delta_{k w m y}+\gamma X_{s y} \zeta_{k w}+\varepsilon_{k s w m y}
\end{aligned}
$$

where $\log q_{\text {kswmy }}$ denotes the $\log$ quantity of product $k$ purchased in store $s$ in week $w$ in month $m$ of year $y, \log P_{k s w m y}$ denotes the $\log$ price of that product in the corresponding store-week, $\alpha_{k s m y}$ denotes product-store-month fixed effects, $\delta_{k w m y}$ denotes product-week fixed effects, $X_{s y}$ denotes year-level characteristics of the state in which the store is located, and $\zeta_{k w}$ denotes product by calendar week fixed effects. We restrict this product-level analysis to the top 100 food products by expenditure share among SNAP-eligible shoppers. ${ }^{29}$ The main parameter of interest in this model is $\eta$, which measures the change in price elasticity for a good between a week in which $100 \%$ of SNAP benefits are issued and a week in which no benefits are issued. As in the prior sections, the $\delta_{k w m y}$ term captures within-month variation in a product's elasticity that is due to factors other than SNAP issuance. We also consider variants of equation (6) that implement a difference-in-differences specification by including product by store by calendar week fixed effects, $\phi_{k s w}$.

An important concern with the analysis described in the prior paragraph is that a regression of quantity on price may fail to recover the true elasticity estimates if there are issues of reverse causality (i.e., within-month demand shocks could induce stores to adjust prices). To address this possibility, we follow Hausman (1996) as adapted in DellaVigna and Gentzkow (2019) and instrument for the price of a product in a store using the price of the product at

\footnotetext{
${ }^{29}$ More specifically, these products are those estimated from the Consumer Panel to have the highest expenditure share among SNAP-eligible customers among all food products that were purchased in at least $80 \%$ of the store-weeks in our data. The $80 \%$ threshold corresponds to the availability restriction imposed by DellaVigna and Gentzkow (2019) to select the products included in their analysis. Appendix Table A.14 shows the estimated effects of SNAP issuance on quantity purchased and prices are similar for this subset of products and our main sample. In addition, to ensure that missing price data is not driving our findings for this sample, Appendix Table A.15 imputes prices for products that are missing in a given store-week with the average observed price of the product among stores belonging to the same chain within the same state in the specified week; the results are qualitatively similar to our main specification, which excludes products that are missing in at least one week in a given store-month.
} 
stores within the same chain but located in other regions (technically, "Designated Market Areas" or DMA). Under the assumption that local demand shocks for a store do not affect chain-level pricing decisions (conditional on our other controls), this analysis identifies the causal effect of a product's price on the quantity that consumers demand. As in DellaVigna and Gentzkow (2019), we estimate the first-stage effect of the instrument on prices to be close to 1 (see Appendix Table A.16).

Columns 1 and 2 of Table 3 present the estimated effect of SNAP issuance on price elasticity $(\eta)$, as well as the estimated effects of prices $(\mu)$ and SNAP issuance $(\beta)$ on the quantity of a product purchased, from the OLS regression described in equation (6). Our results suggest that customers are slightly more price-elastic in weeks that SNAP benefits are issued, especially in high-SNAP stores. For example, in stores located in high-SNAP neighborhoods, our difference-in-differences specification yields an estimated coefficient of 0.03 for the price by issuance share interaction, suggesting that aggregate consumer demand becomes approximately $1.6 \%$ more elastic in weeks in which all SNAP benefits are issued compared to weeks in which no benefits are issued. The IV specification (Columns 3 and 4) yield similar but slightly smaller point estimates - especially for the difference-in-differences specification, for which the estimated elasticity change is only $0.6 \%$ for the high-SNAP stores and is not statistically significant.

The small observed change in aggregate demand elasticities associated with SNAP issuance suggests that large price changes in response to SNAP issuance may not be profitmaximizing. To link these estimated elasticities to pricing responses, Appendix A draws on a simple model of grocer pricing, in which grocery stores have local market power due to the fact that customers are constrained by travel costs and perishable foods (as in Ellickson, Houghton, and Timmins (2013) and Ellickson (2006)). Using this model, we derive the optimal price response of grocery stores as a function of changes in consumer price elasticities over the course of the month. Table 3 includes these predicted price responses under the elasticity estimates for the corresponding specification and sample. The results suggest that 
stores should slightly reduce food prices in weeks that SNAP benefits are issued. Focusing on the IV specification, our estimates suggest that stores should reduce prices between 0.1 and 0.8 percent in weeks in which all benefits are issued relative to weeks in which no benefits are issued.

The elasticity results in conjunction with this simple model suggest retailers should modestly reduce food prices in response to SNAP issuance. However, even these modest reductions are outside our 95\% confidence interval for the effect of SNAP issuance on prices - an estimated effect that is near-zero and very slightly positive 30

One factor missing from our analysis that could potentially explain this discrepancy is the possibility that SNAP issuance affects grocery stores' marginal costs. For example, stores may increase staffing in weeks that SNAP benefits are issued to handle the increased flow of customer traffic (e.g., Cloud 2012). To the extent SNAP issuance raises stores' marginal costs in this way, it may offset the incentive to lower prices from SNAP-induced changes in consumer elasticities 31

As noted above, a potential reason why stores do not adjust prices in response to SNAP issuance is that the benefits of doing so may be quite small, given the small predicted price changes implied by our elasticity estimates. A complementary explanation for the lack of pricing response could be the adjustment or managerial decision costs that a store would incur by varying its prices in response to SNAP issuance cycles (Hanna, Mullainathan, and Schwartzstein 2014; Bloom et al. 2013). For example, DellaVigna and Gentzkow (2019) find that such costs contribute to uniform pricing decisions across grocery stores belonging to the same chain. The SNAP-induced elasticity changes over the course of a month are smaller than the elasticity differences across stores documented by DellaVigna and Gentzkow (2019);

\footnotetext{
${ }^{30}$ Taking the prescriptions of this stylized model as optimal would suggest that, by failing to reduce prices in response to SNAP issuance, retailers are forgoing profits, SNAP recipients are facing higher food prices during their shopping trips, and non-recipients who disproportionately shop in weeks that benefits are not issued are benefiting from the (relatively) lower food prices.

${ }^{31}$ In principle, SNAP-induced variation in marginal costs could create a net incentive for firms to raise prices in response to SNAP issuance, notwithstanding the observed effects on customer elasticities. Our near-zero price effects thus provide some evidence against this possibility as well.
} 
as such, it would not be surprising that similar factors limit grocery store price adjustments based on SNAP issuance cycles.

To assess the contribution of factors other than small elasticity changes (such as managerial inertia) in explaining stores' lack of price responses, Appendix Figure A.4 disaggregates our results to explore the relationship between SNAP-induced variation in elasticities and prices. In particular, there may be larger changes in customer demand elasticity within subsets of the data - e.g., certain products - along with correspondingly larger fluctuations in price. To investigate this possibility, Appendix Figure A.4plots the estimated effects of SNAP issuance, by product, on prices and elasticities. If small changes in elasticities were the only factor responsible for the lack of observed price effects, we would expect to observe larger price changes for those products experiencing larger changes in elasticities. However, the slope of the best linear-fit is near zero, providing no evidence for such a pattern. Thus, while small elasticities and associated small incentives to vary prices could certainly contribute to lack of observed price, this analysis provides suggestive evidence that other factors may be at play as well.

Finally, pricing strategies that require managers to set weekly prices differently across stores may be costlier to implement than pricing strategies that vary prices by week but that are uniform within a week across stores within a given chain. To explore the role played by this specific type of managerial cost in limiting store pricing responses, we focus on a subset of stores in which adjusting to SNAP issuance would not require different pricing policies across stores within a chain. In particular, Appendix Figure A.5 replicates Appendix Figure A.4. limiting the analysis to chains for which all stores are located entirely within a single state or entirely within a set of states that have uniform SNAP issuance schedules. Among stores located in high-SNAP neighborhoods, the figure suggests a small but positive relationship between SNAP-induced elasticity and pricing changes, closer to the predictions of the simple model. The results therefore provide suggestive evidence that managerial inertia may help explain why stores do not set prices based on intra-month cycles in SNAP issuance. 


\section{Conclusion}

In this paper we study intra-month patterns in customer demand and retail pricing driven by SNAP issuance. We find that SNAP issuance causes large increases in food expenditures but little to no change in retail food prices. We investigate several potential explanations for the lack of price response. For example, notwithstanding the large effects on demand induced by SNAP issuance, we observe small effects of issuance on the price elasticity of demand facing retailers, which may limit their incentives to adjust prices in response to the SNAP issuance schedule. Although we do not provide direct evidence for them, our results are also consistent with factors such as changing marginal labor supply costs or managerial inertia contributing to the lack of observed price response.

Our results have implications for the likely effect of policy reforms that alter the SNAP issuance schedule. For example, as we have discussed, a number of states have staggered their SNAP issuance schedules to spread out the dates on which different individuals receive their monthly allotment of benefits. Similarly, some have proposed splitting the issuance of SNAP benefits to a given individual into multiple payment dates within a single month (e.g., Wilde and Ranney 2000; Hastings and Washington 2010; Dorfman et al. 2019).

First, our findings related to food expenditure cyclicality shed light on how such reforms are likely to affect customers shopping behavior. In particular, because we find that food expenditure cyclicality is due to SNAP issuance - rather than some other monthly pattern our results suggest that state reforms to either split or stagger issuance would have the effect of reducing fluctuations in the aggregate food demand faced by retailers. Consequently, by smoothing food demand across the month, our findings support the notion that reforms to SNAP issuance schedules can reduce grocery costs associated with surges in customer traffic, such as long lines or difficulty stocking shelves or staffing stores.

In addition, because we find that these reforms would shape the food demand cyclicality faced by retailers, our results suggest that they may also shape the incidence of SNAP benefits. That is, to the extent retailers face predictable fluctuations in the nature of consumer 
food demand, it may, in principle, be profit-maximizing for them to adjust food prices over the course of the month. If retailers were to adjust food prices during the weeks that SNAP recipients purchase food, such behavior may increase or decrease the purchasing power of the benefits. Hence, assessing the welfare effect of reforms to SNAP issuance schedules requires understanding the link between issuance and retailer pricing decisions. Because we find evidence that retailers do not adjust food prices in this way, our results suggest that concerns relating to the incidence of benefits should not play a large role in state decisions about whether to adjust their issuance schedules. 


\section{References}

Beatty, Timothy KM, Marianne P Bitler, Xinzhe Huang Cheng, and Cynthia Van der Werf. 2019. "SNAP and paycheck cycles." Southern Economic Journal 86 (1): $18-48$.

Bloom, Nicholas, Benn Eifert, Aprajit Mahajan, David McKenzie, and John Roberts. 2013. "Does management matter? Evidence from India." The Quarterly Journal of Economics 128 (1): 1-51.

Castellari, Elena, Chad Cotti, John Gordanier, and Orgul Ozturk. 2017. "Does the Timing of Food Stamp Distribution Matter? A Panel-Data Analysis of Monthly Purchasing Patterns of US Households." Health economics 26 (11): 1380-1393.

Castner, Laura, and Juliette Henke. 2011. Benefit Redemption Patterns in the Supplemental Nutrition Assistance Program. Technical report. USDA-FNS Report.

Census Bureau. 2012. Poverty Status in the Past 12 Months (S1701), 2008-2012 American Community Survey 5 Year Estimates. http://factfinder. census.gov, accessed on 1/1/2019. U.S. Census Bureau.

Center on Budget and Policy Priorities. 2018. A Quick Guide to SNAP Eligibility and Benefits. https : / /www . cbpp . org/research/food-assistance/a-quick-guideto-snap-eligibility-and-benefits, accessed on 4/10/2019. Center on Budget and Policy Priorities.

Chevalier, Judith A., Anil K. Kashyap, and Peter E. Rossi. 2003. "Why Don't Prices Rise During Periods of Peak Demand? Evidence from Scanner Data." The American Economic Review 93 (1): 15.

Clark, Krissy. 2020. "The Secret Life of a Food Stamp Might Become a Little Less Secret." Slate.

Cloud, Kristen. 2012. "SNAP Benefit Issuance Changes in October, Doubles Number of Distribution Days." The Shelby Report.

DellaVigna, Stefano, and Matthew Gentzkow. 2019. "Uniform Pricing in U.S. Retail Chains." The Quarterly Journal of Economics 134, no. 4 (June): 2011-2084.

Dorfman, Jeffrey H, Christian Gregory, Zhongyuan Liu, and Ran Huo. 2019. "Reexamining the SNAP benefit cycle allowing for heterogeneity." Applied Economic Perspectives and Policy 41 (3): 404-433.

Duggan, Mark, and Fiona M. Scott Morton. 2006. "The Distortionary Effects of Government Procurement: Evidence from Medicaid Prescription Drug Purchasing." The Quarterly Journal of Economics 121 (1): 1-30. 
Ellickson, Paul B. 2006. "Quality Competition in Retailing: A Structural Analysis." International Journal of Industrial Organization 24, no. 3 (May): 521-40.

Ellickson, Paul B., Stephanie Houghton, and Christopher Timmins. 2013. "Estimating Network Economies in Retail Chains: a Revealed Preference Approach." The RAND Journal of Economics 44, no. 2 (June): 169-93.

Ganong, Peter, and Jeffrey B Liebman. 2018. "The decline, rebound, and further rise in SNAP enrollment: Disentangling business cycle fluctuations and policy changes." American Economic Journal: Economic Policy 10 (4): 153-76.

Gennetian, Lisa A, Roopa Seshadri, Nathan D Hess, Aaron N Winn, and Robert M Goerge. 2016. "Supplemental Nutrition Assistance Program (SNAP) benefit cycles and student disciplinary infractions." Social Service Review 90 (3): 403-433.

Goodman-Bacon, Andrew. 2018. Difference-in-differences with variation in treatment timing. Technical report. National Bureau of Economic Research.

Gray, Kelsey Farson, and Karen Cunnyngham. 2016. Trends in Supplemental Nutrition Assistance Program Participation Rates: Fiscal Year 2010 to Fiscal Year 2015. Technical report. Mathematica Policy Research.

Gregory, Christian A, and Travis A Smith. 2019. "Salience, food security, and SNAP receipt." Journal of Policy Analysis and Management 38 (1): 124-154.

Hamrick, Karen S, and Margaret Andrews. 2016. "SNAP participants eating patterns over the benefit month: a time use perspective." PloS one 11 (7): e0158422.

Handbury, Jessie, and Sarah Moshary. 2020. School Food Policy Affects Everyone: Retail Responses to the National School Lunch Program. Technical report. Working Paper.

Hanna, Rema, Sendhil Mullainathan, and Joshua Schwartzstein. 2014. "Learning through noticing: Theory and evidence from a field experiment." The Quarterly Journal of Economics 129 (3): 1311-1353.

Hastings, Justine, and Jesse M. Shapiro. 2018. "How Are SNAP Benefits Spent? Evidence from a Retail Panel." American Economic Review 108, no. 12 (December): 34933540 .

Hastings, Justine, and Ebonya Washington. 2008. The First of the Month Effect: Consumer Behavior and Store Responses. Working Paper, Working Paper Series 14578. National Bureau of Economic Research, December.

. 2010. "The First of the Month Effect: Consumer Behavior and Store Responses." American Economic Journal: Economic Policy 2 (2): 142-62. 
Hausman, Jerry A. 1996. "Valuation of new goods under perfect and imperfect competition." In The economics of new goods, 207-248. University of Chicago Press.

Jaravel, Xavier. 2018. "What Is the Impact of Food Stamps on Prices and Products Variety? The Importance of the Supply Response." AEA Papers and Proceedings 108 (May): $557-61$.

Leftin, Joshua, Esa Eslami, and Mark Strayer. 2011. Trends in Supplemental Nutrition Assistance Program Participation Rates: Fiscal Year 2002 to Fiscal Year 2009. Technical report. Mathematica Policy Research.

Leung, Justin, and Hee Kwon Seo. 2019. "How Do Government Transfer Payments Affect Retail Prices and Welfare? Evidence from SNAP." Working Paper.

Makioka, Ryo. 2018. "Decomposing the Effect of SNAP." Working Paper.

Mastrobuoni, Giovanni, and Matthew Weinberg. 2009. "Heterogeneity in Intra-Monthly Consumption Patterns, Self-Control, and Savings at Retirement." American Economic Journal: Economic Policy 1 (2): 163-189.

Meckel, Katherine. 2020. "Is the Cure Worse Than the Disease? Unintended Effects of Payment Reform in a Quantity-Based Transfer Program." American Economic Review 110 (6): 1821-1865.

Nevo, Aviv. 2001. "Measuring market power in the ready-to-eat cereal industry." Econometrica 69 (2): 307-342.

Rothstein, Jesse. 2010. "Is the EITC as good as an NIT? Conditional cash transfers and tax incidence." American Economic Journal: Economic Policy 2 (1): 177-208.

Seligman, Hilary K, Ann F Bolger, David Guzman, Andrea López, and Kirsten Bibbins-Domingo. 2014. "Exhaustion of food budgets at monthfffdfffdfffds end and hospital admissions for hypoglycemia." Health affairs 33 (1): 116-123.

Shapiro, Jesse M. 2005. "Is There a Daily Discount Rate? Evidence from the Food Stamp Nutrition Cycle." Journal of Public Economics 89 (2): 303-325.

Smith, Travis A, Joshua P Berning, Xiaosi Yang, Gregory Colson, and Jeffrey H Dorfman. 2016. "The effects of benefit timing and income fungibility on food purchasing decisions among Supplemental Nutrition Assistance Program households." American Journal of Agricultural Economics 98 (2): 564-580.

Stephens Jr., Melvin. 2003. "3rd of tha Month": Do Social Security Recipients Smooth Consumption Between Checks?" American Economic Review: 406-422. 
Stephens Jr., Melvin. 2006. "Paycheque Receipt and the Timing of Consumption." The Economic Journal 116 (513): 680-701.

Stroebel, Johannes, and Joseph Vavra. 2019. "House Prices, Local Demand, and Retail Prices." Journal of Political Economy 127, no. 3 (June): 1391-1436.

Todd, Jessica E. 2015. "Revisiting the Supplemental Nutrition Assistance Program cycle of food intake: Investigating heterogeneity, diet quality, and a large boost in benefit amounts." Applied Economic Perspectives and Policy 37 (3): 437-458.

U.S. Department of Agriculture. 2013. What Can SNAP Buy? https://www . fns . usda gov/snap/eligible-food-items, accessed on 4/10/2019. USDA Food and Nutrition Service.

USDA-FNS. 2019. Supplemental Nutrition Assistance Program Participation and Costs. Technical report.

Wilde, Parke E. 2012. "The New Normal: The Supplemental Nutrition Assistance Program (SNAP)." American Journal of Agricultural Economics 95 (2): 325-331.

Wilde, Parke E, and Christine K Ranney. 2000. "The Monthly Food Stamp Cycle: Shopping Frequency and Food Intake Decisions in an Endogenous Switching Regression Framework." American Journal of Agricultural Economics 82 (1): 200-213. 


\section{Figure 1: Food Expenditures by Weekly SNAP Issuance}

(a) All Stores

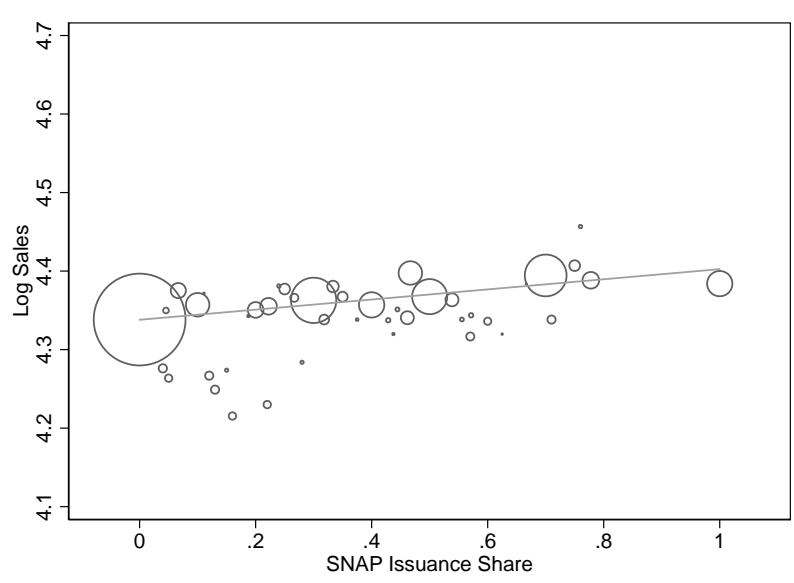

(b) High-SNAP Stores

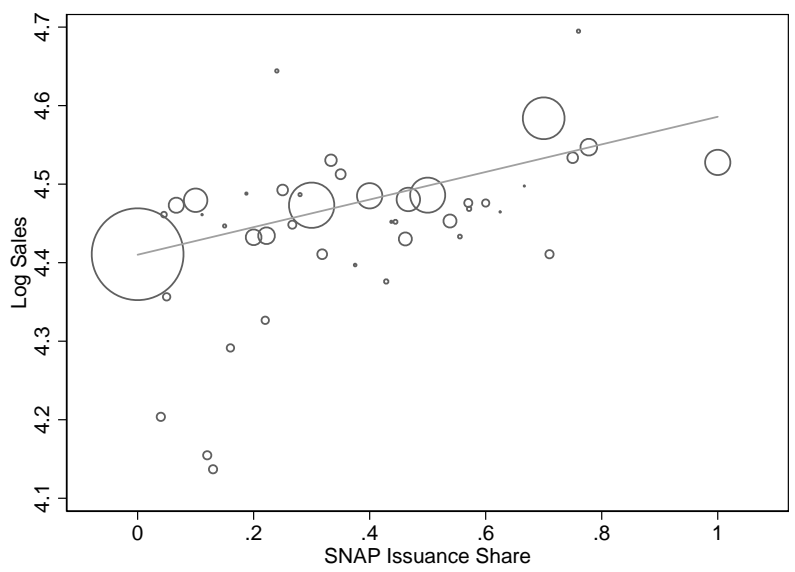

Notes: The figure displays average log food expenditures by the share of SNAP benefits issued in a given week of the month. Log food expenditures are aggregated across products using weights derived from purchases by SNAP-eligible shoppers. SNAP Issuance Share reflects the share of SNAP benefits issued during a calendar week in the jurisdiction in which a store is located. Points in the figure are proportionate to the number of store-weeks with the specified issuance share and reflect residuals after controlling for store-year-month and year-month-week fixed effects. Panel A contains all stores in the sample; Panel B is limited to stores for which we estimate that the share of SNAP recipients in the ZIP code is at least $20 \%$. The estimated slope of the best linear-fit (weighted by the number of store-weeks with the specified issuance share) is 0.06 in Panel A and 0.18 in Panel B. 
Figure 2: Food Expenditure Cyclicality by Local SNAP Prevalence
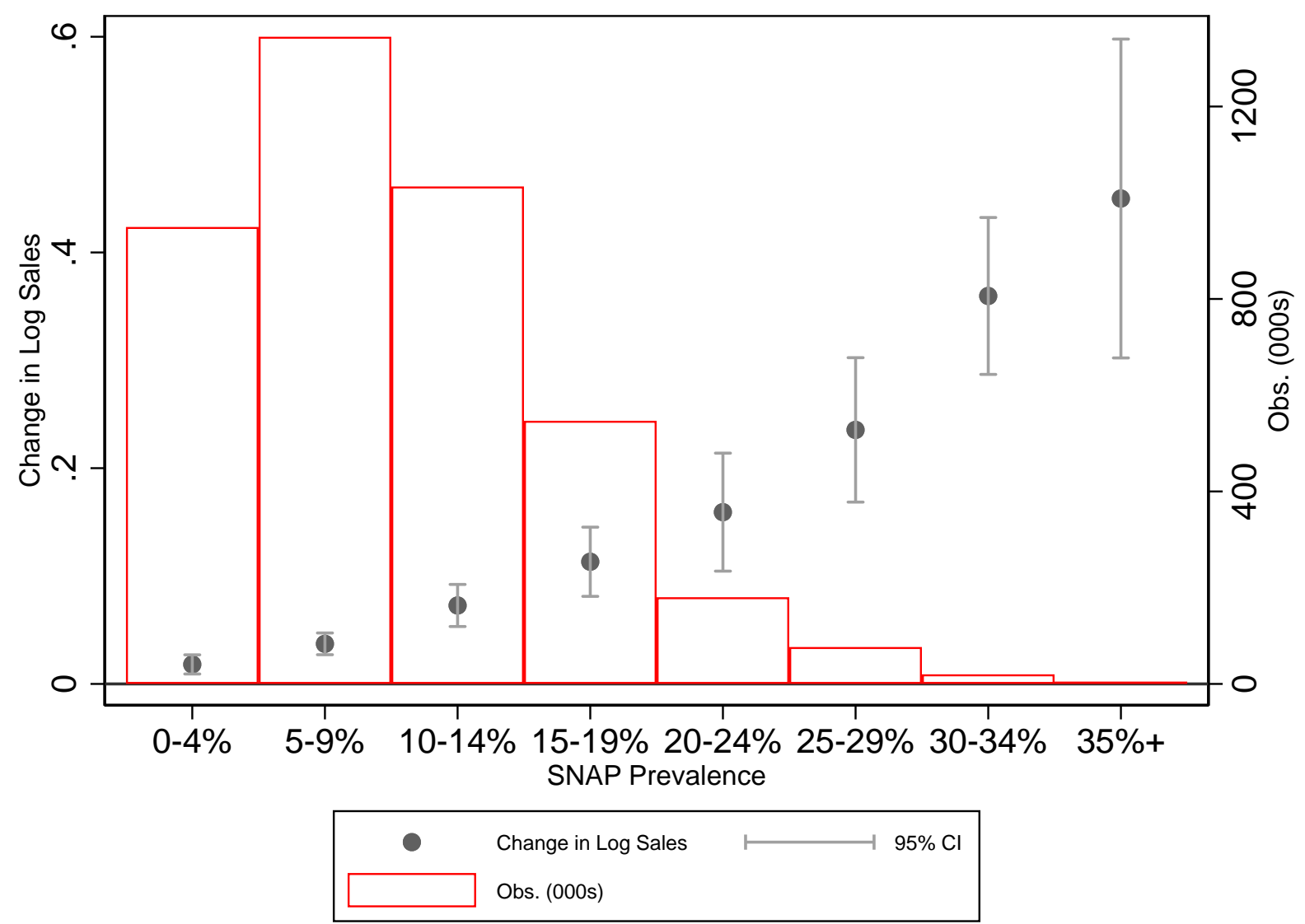

Notes: The figure displays the estimated effect of SNAP issuance on log food expenditures by local SNAP prevalence. Local SNAP prevalence refers to the estimated share of the population that are SNAP recipients in the ZIP code in which the grocery store is located. Log food expenditures are aggregated across products using weights derived from purchases by SNAP-eligible shoppers. Change in log sales refers to the estimated coefficient on SNAP Issuance Share, which is defined as the share of SNAP benefits issued during a given week of the month in the jurisdiction in which a store is located. The effect of SNAP issuance on log food expenditures is estimated from a specification that controls for store-year-month and year-month-week fixed effects, as well as the interaction of calendar week with log state population, $\log$ gross domestic product, and unemployment rate (corresponding to Column 3 in Table 1). The error bars on the estimated effects reflect the $95 \%$ confidence interval from standard errors clustered by state. The hollow bars reflect the number of observations in our sample (i.e., the number of store-weeks) from stores located in ZIP codes with the specified population share of SNAP recipients. 
Figure 3: Event-Study Analysis of SNAP Issuance Reforms on Food Expenditure Cyclicality

(a) All Stores

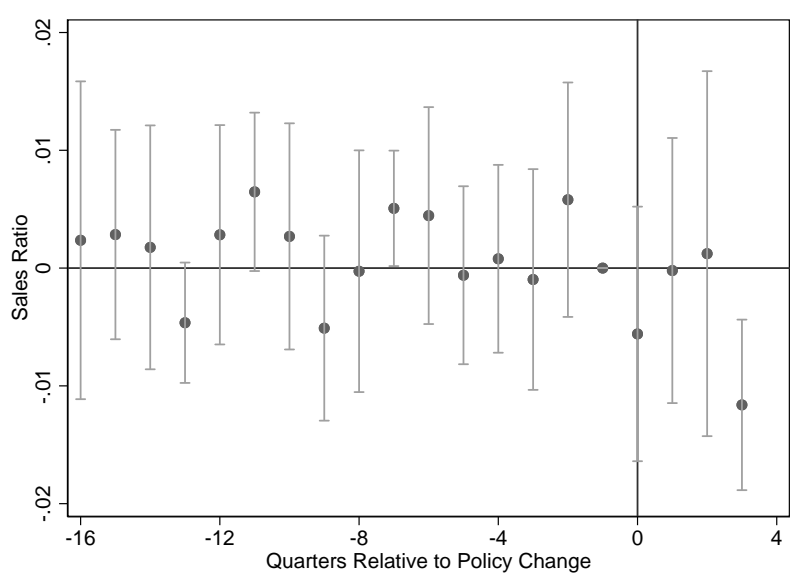

(b) High-SNAP Stores

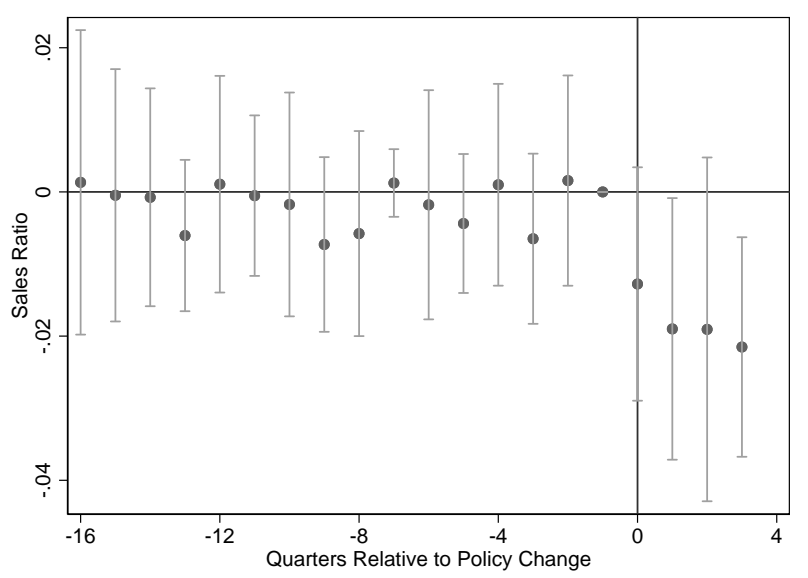

Notes: The figure displays the event-study analysis of the effect of policy reforms that staggered SNAP issuance on the timing of food expenditures. The outcome is the ratio of monthly log food expenditures occurring in the first two calendar weeks relative to monthly log food expenditures occurring during the full month. Log food expenditures are aggregated across products using weights derived from purchases by SNAP-eligible shoppers. The estimates reflect the effect of policy reforms in the ten states that expanded the share of benefits issued during the third and fourth calendar weeks of the month during our sample period (see Appendix Table A.1). The analysis excludes the two states (Oklahoma and Virginia) that altered the share of SNAP benefits issued across calendar weeks during our sample period but that did not expand the share of benefits issued during the third and fourth calendar weeks of the month. The analysis also excludes Idaho, which reformed its issuance schedule during our sample period but did not alter the share of benefits issued across calendar weeks. The estimated effects are derived from a specification that controls for store-year-month and year-month-week fixed effects and that omits a coefficient for the effect of the intervention in the quarter prior to implementation (the reference period). Panel A contains all stores in the sample; Panel B is limited to stores for which we estimate that the share of SNAP recipients in the ZIP code is at least $20 \%$. The brackets surrounding the estimated effects reflect the $95 \%$ confidence interval from standard errors clustered by state. 


\section{Figure 4: Food Prices by Weekly SNAP Issuance}

(a) All Stores

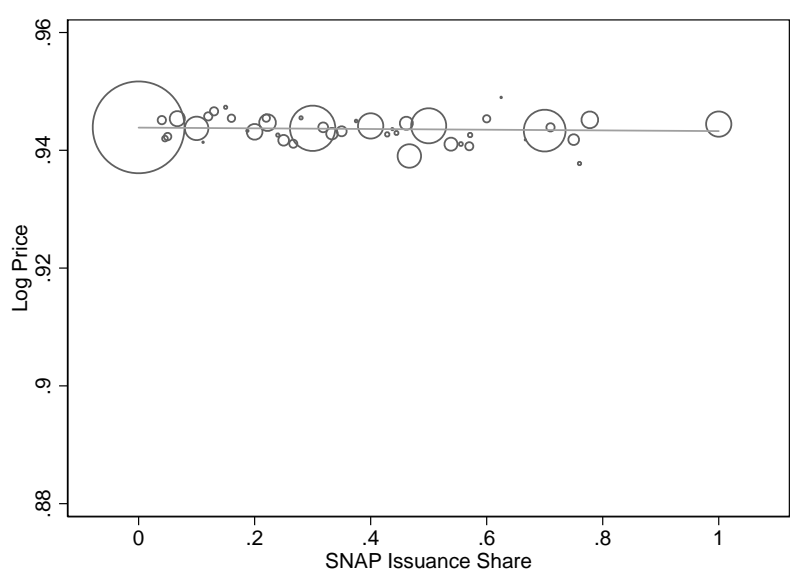

(b) High-SNAP Stores

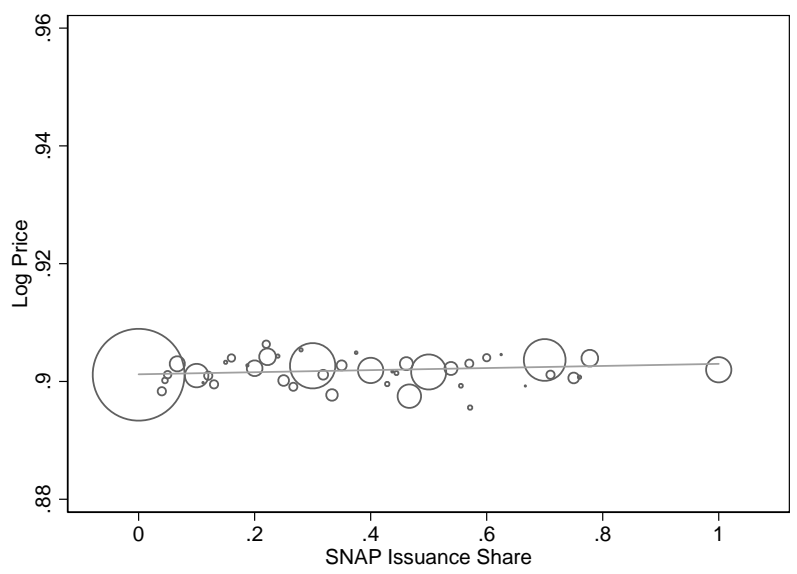

Notes: The figure displays average log food prices by the share of SNAP benefits issued in a given week of the month. Prices in a store-week correspond to an index of product-level log prices; the index is derived from purchases by SNAP-eligible shoppers. SNAP Issuance Share reflects the share of SNAP benefits issued during a calendar week in the jurisdiction in which a store is located. Points in the figure are proportionate to the number of store-weeks with the specified issuance share and reflect residuals after controlling for store-year-month and year-month-week fixed effects. Panel A contains all stores in the sample; Panel B is limited to stores for which we estimate that the share of SNAP recipients in the ZIP code is at least $20 \%$. The estimated slope of the best linear-fit (weighted by the number of store-weeks with the specified issuance share) is -0.001 in Panel A and 0.002 in Panel B. 
Figure 5: Food Price Cyclicality by Local SNAP Prevalence
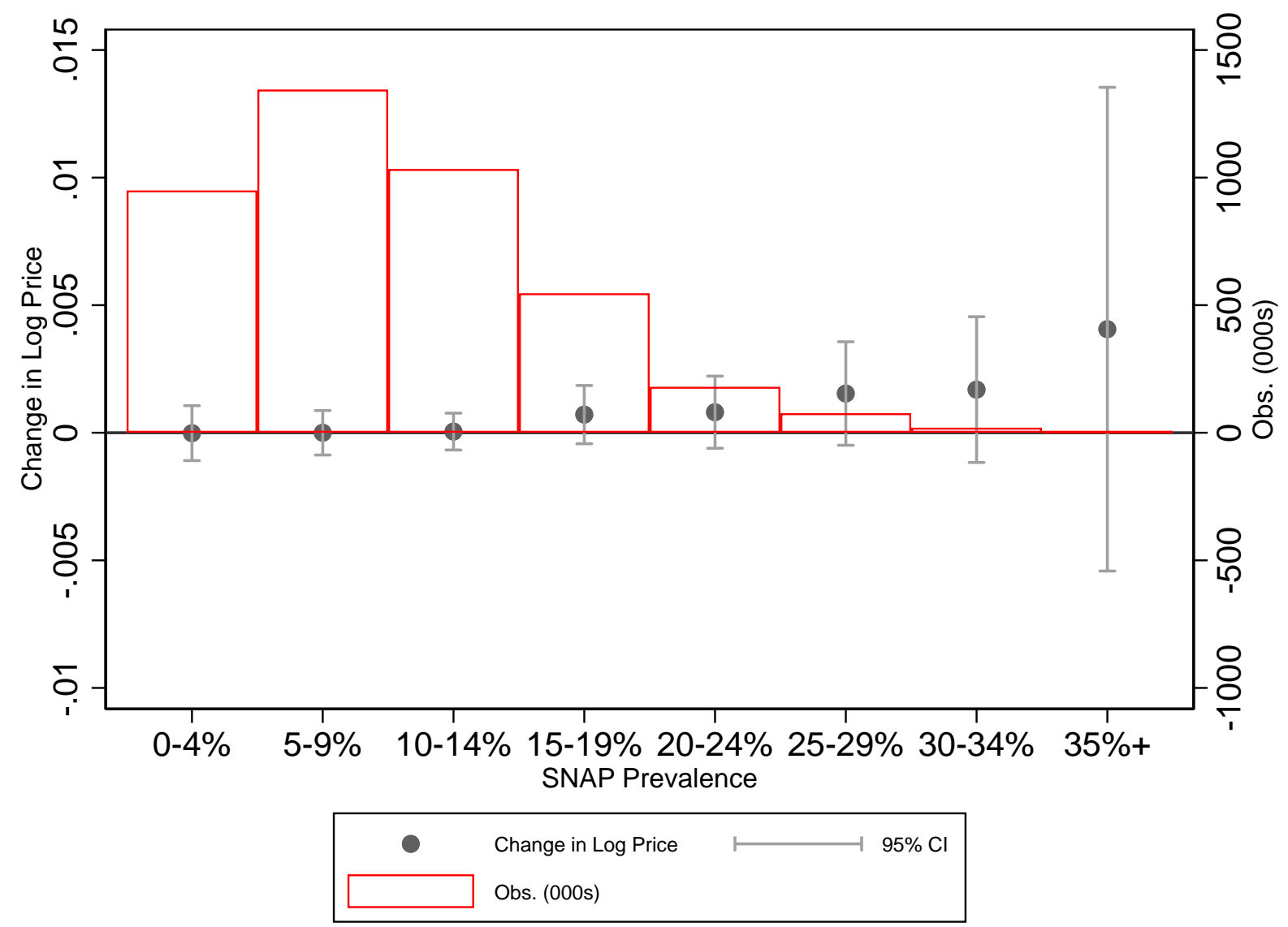

Notes: The figure displays the estimated effect of SNAP issuance on log food prices by local SNAP prevalence. Local SNAP prevalence refers to the estimated share of the population that are SNAP recipients in the ZIP code in which the grocery store is located. Prices in a store-week correspond to an index of product-level log prices; the index is derived from purchases by SNAP-eligible shoppers. Change in $\log$ prices refers to the estimated coefficient on SNAP Issuance Share, which reflects the share of SNAP benefits issued during a given week of the month in the jurisdiction in which a store is located. The effect of SNAP issuance on log food prices is estimated from a specification that controls for store-year-month and year-month-week fixed effects, as well as the interaction of calendar week with log state population, $\log$ gross domestic product, and unemployment rate (corresponding to Column 3 in Table 2). The error bars on the estimated effects reflect the $95 \%$ confidence interval from standard errors clustered by state. The hollow bars reflect the number of observations in our sample (i.e., the number of store-weeks) from stores located in ZIP codes with the specified population share of SNAP recipients. 
Table 2: The Effect of SNAP Issuance on Food Price Cyclicality

\begin{tabular}{rccccc}
\hline & $(1)$ & $(2)$ & $(3)$ & $(4)$ & $(5)$ \\
\hline Panel A: All Stores & & & & & \\
Issuance Share & $-0.0013^{* * *}$ & 0.0004 & 0.0002 & 0.0010 & 0.0010 \\
& $(0.0004)$ & $(0.0004)$ & $(0.0004)$ & $(0.0008)$ & $(0.0009)$ \\
$\mathrm{N}$ & $4,157,698$ & $4,157,698$ & $4,157,698$ & $4,157,698$ & $4,157,698$ \\
\hline Panel B: High-SNAP Stores & & & & & \\
Issuance Share & $-0.0014^{*}$ & 0.0011 & 0.0011 & 0.0014 & 0.0014 \\
& $(0.0008)$ & $(0.0008)$ & $(0.0007)$ & $(0.0012)$ & $(0.0014)$ \\
& 281,739 & 281,739 & 281,739 & 281,739 & 281,739 \\
\hline Controls & & & & & \\
Store-Year-Month & $\mathrm{X}$ & $\mathrm{X}$ & $\mathrm{X}$ & $\mathrm{X}$ & $\mathrm{X}$ \\
Year-Month-Calendar Week & & $\mathrm{X}$ & $\mathrm{X}$ & $\mathrm{X}$ & $\mathrm{X}$ \\
Calendar Week * Controls & & & $\mathrm{X}$ & & $\mathrm{X}$ \\
Calendar Week * Store & & & & $\mathrm{X}$ & $\mathrm{X}$
\end{tabular}

Notes: The table shows the effect of SNAP issuance on log food prices at a given store in a given week of the month. Prices in a store-week correspond to an index of product-level log prices; the index is derived from purchases by SNAP-eligible shoppers. Issuance Share reflects the share of SNAP benefits issued during a calendar week in the jurisdiction in which a store is located. Panel A contains all stores in the sample; Panel B is limited to stores for which we estimate that the share of SNAP recipients in the ZIP code is at least $20 \%$. All columns include store by year by month fixed effects. Columns 2-5 include year by month by week fixed effects. Columns 3 and 5 include interactions of calendar week with state-year measures of $\log$ population, log GDP per capita, and unemployment rate. Columns 4 and 5 include calendar week by store fixed effects. All specifications are weighted by average annual store volume. Standard errors, reported in parentheses, are clustered by state. ${ }^{*} p<0.10,{ }^{* *} p<0.05,{ }^{* * *} p<0.01$. 
Table 3: Elasticity Estimates, 100 UPCs

\begin{tabular}{|c|c|c|c|c|}
\hline & \multicolumn{2}{|c|}{ OLS } & \multicolumn{2}{|c|}{ IV } \\
\hline & $(1)$ & $(2)$ & $(3)$ & $(4)$ \\
\hline \multicolumn{5}{|l|}{ Panel A: All Stores } \\
\hline Price X & $-0.0216^{* * *}$ & $-0.0145^{*}$ & $-0.0207^{* * *}$ & -0.0056 \\
\hline Issuance Share & $(0.0045)$ & $(0.0082)$ & $(0.0043)$ & $(0.0095)$ \\
\hline Price & $-2.1025^{* * *}$ & $-2.0857^{* * *}$ & $-2.5917^{* * *}$ & $-2.5764^{* * *}$ \\
\hline & $(0.1236)$ & $(0.1250)$ & $(0.1265)$ & $(0.1253)$ \\
\hline \multirow[t]{2}{*}{ Issuance Share } & $0.0825^{* * *}$ & $0.1024^{* * *}$ & $0.0818^{* * *}$ & $0.0962^{* * *}$ \\
\hline & $(0.0107)$ & $(0.0169)$ & $(0.0108)$ & $(0.0186)$ \\
\hline $\mathrm{N}$ & $379,212,892$ & $379,212,892$ & $379,212,892$ & $379,212,892$ \\
\hline Optimal Price Change & $-0.9 \%$ & $-0.6 \%$ & $-0.5 \%$ & $-0.1 \%$ \\
\hline \multicolumn{5}{|c|}{ Panel B: High-SNAP Stores } \\
\hline Price $\mathrm{X}$ & $-0.0385^{* * *}$ & $-0.0323^{*}$ & $-0.0350^{* * *}$ & -0.0161 \\
\hline Issuance Share & $(0.0092)$ & $(0.0164)$ & $(0.0080)$ & $(0.0181)$ \\
\hline Price & $-2.0657^{* * *}$ & $-2.0202^{* * *}$ & $-2.6396^{* * *}$ & $-2.5747^{* * *}$ \\
\hline \multirow{3}{*}{ Issuance Share } & $(0.1601)$ & $(0.1562)$ & $(0.2168)$ & $(0.2064)$ \\
\hline & $0.2335^{* * *}$ & $0.2425^{* * *}$ & $0.2309^{* * *}$ & $0.2329^{* * *}$ \\
\hline & $(0.0357)$ & $(0.0330)$ & $(0.0362)$ & $(0.0354)$ \\
\hline $\mathrm{N}$ & $24,576,132$ & $24,576,132$ & $24,576,132$ & $24,576,132$ \\
\hline Implied Price Change & $-1.7 \%$ & $-1.5 \%$ & $-0.8 \%$ & $-0.4 \%$ \\
\hline Calendar Week * Store & No & Yes & No & Yes \\
\hline
\end{tabular}

Notes: The table shows the effect of SNAP issuance and price on quantity sold at a given store in a given week of the month. The analysis is conducted on the top 100 food products by expenditure share among SNAPeligible shoppers, subject to the limitation that the product was purchased in at least $80 \%$ of store-weeks. The unit of observation is a product-store-week. The outcome is the log quantity of food products purchased in a given store-week. Issuance Share reflects the share of SNAP benefits issued during a calendar week in the jurisdiction in which a store is located. Price refers to the log of a products price in a given store-week. Implied price change refers to the difference in optimal prices between a week in which all SNAP benefits are issued and a week in which no SNAP benefits are issued, based on the estimated elasticity and the monopoly pricing model described in the Appendix. In Columns 1 and 2, the coefficients are obtained by estimating equation (6) in the text. In Columns 3 and 4, the coefficients are obtained from a two-stage least-squares estimate, in which a product's price in a given store-week is instrumented for with the price of the product in stores of the same chain but located in other Designated Market Areas. All columns include product by store by year by month fixed effects, product by year by month by week fixed effects, and interactions of product by calendar week with state-year measures of log population, log GDP per capita, and unemployment rate. Columns 2 and 4 additionally include product by calendar week by store fixed effects. Panel A contains all stores in the sample; Panel B is limited to stores for which we estimate that the share of SNAP recipients in the ZIP code is at least $20 \%$. All specifications are weighted by average annual store volume. Standard errors, reported in parentheses, are clustered by state. ${ }^{*} p<0.10,{ }^{* *} p<0.05,{ }^{* * *} p<0.01$. 


\section{A Optimal Pricing Model}

To assess the implications for optimal pricing of the SNAP-induced, within-month variation in sales we estimate above, we use a simple model of retailer profits, similar to the one employed by DellaVigna and Gentzkow (2019), For simplicity, we assume pricing decisions occur at the store, rather than chain, level (or, equivalently, that each chain is comprised of a single store), as we are interested in variation in pricing over time within a given store, rather than across stores within a chain (as in DellaVigna and Gentzkow (2019)).

Grocers have local market power, which follows evidence that customers are constrained due to travel costs and perishable foods (e.g., Ellickson, Houghton, and Timmins 2013; Ellickson 2006). For a given grocer, consumer demand for product $j$ in week $w$ is described by $Q_{j w}=k_{j}\left(P_{j w}\right)^{\eta_{j w}}$, where $Q_{j w}$ is the units of product $j$ that are sold in week $w, k_{j}$ is a product-specific scale term, and $\eta_{j w}$ is the retailer's price elasticity for product $j$ in week $w$, $\eta_{j w}=\frac{\partial Q_{j w}}{\partial P_{j w}} \frac{P_{j w}}{Q_{j w}}$. Stores face product-specific marginal costs $c_{j}$ and fixed costs $C_{j}$, which do not vary by week. The retailer sets weekly prices to maximize:

$$
\max _{\left\{P_{j w}\right\}} \Sigma_{j}\left(P_{j w}-c_{j}\right) Q_{j w}\left(P_{j w}\right)-\Sigma_{j} C_{j}
$$

The first order conditions to this maximization problem imply $P_{j w}=c_{j} \frac{\eta_{j w}}{1-\eta j w}$, or, taking $\operatorname{logs}, \log P_{j w}=\log c_{j}+\log \left(\frac{\eta_{j w}}{1+\eta_{j w}}\right)$. Hence, the percent change in the optimal price for product $j$ between week $w$ and week $w^{\prime}$ is approximately given by

$$
\log P_{j w^{\prime}}-\log P_{j w}=\log \left(\frac{\eta_{j w^{\prime}}}{1+\eta_{j w^{\prime}}}\right)-\log \left(\frac{\eta_{j w}}{1+\eta_{j w}}\right)
$$

Substituting the estimated coefficients from Table 3 into Equation 8 yields our predicted optimal price change between weeks in which all SNAP benefits are issued and weeks in which no benefits are issued. 
Figure A.1: Chain-Level Food Sales Cyclicality by SNAP Prevalence

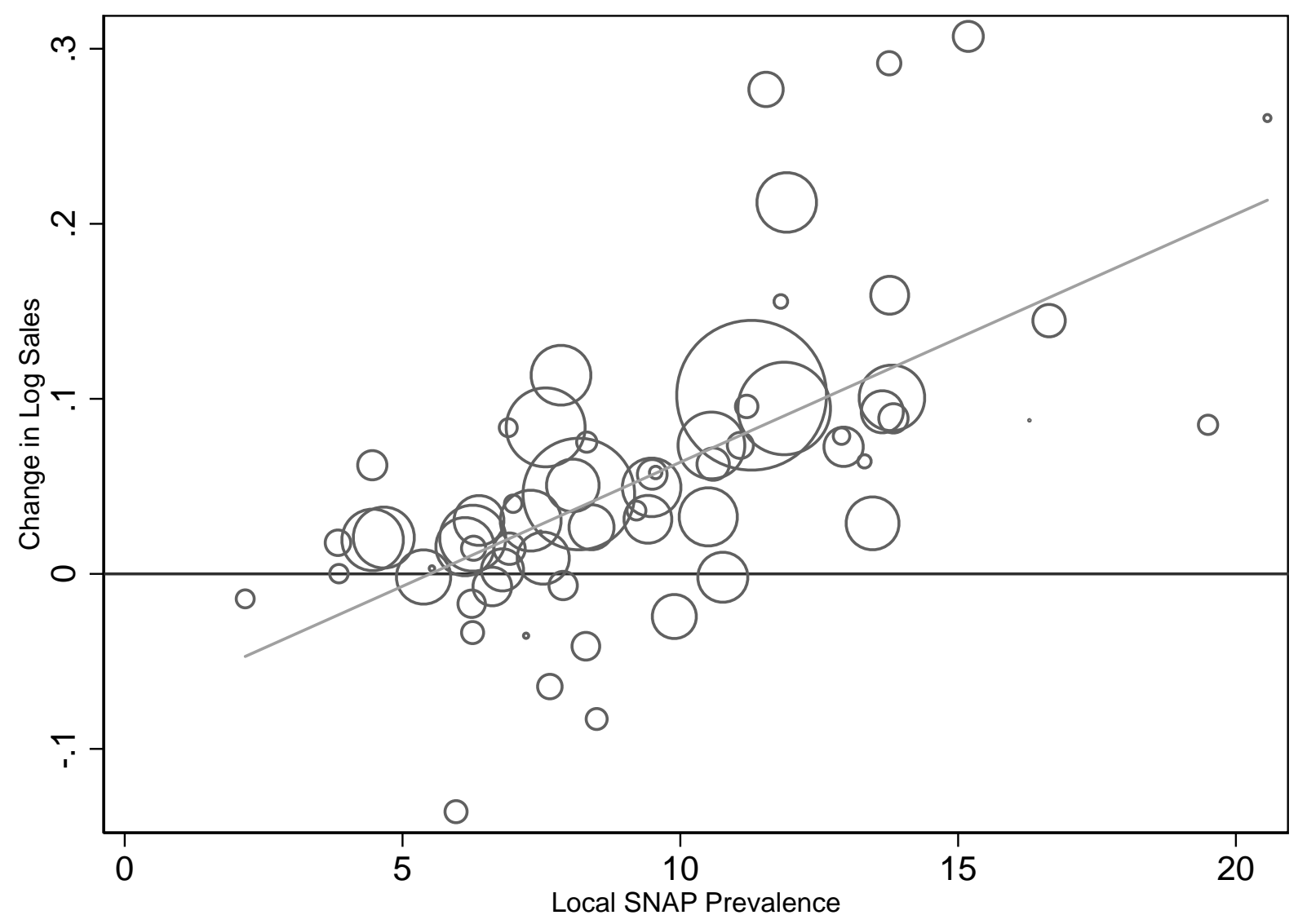

Notes: The figure displays the estimated effect of SNAP issuance on log food expenditures by local SNAP prevalence at the grocery chain level. Each circle corresponds to one grocery store chain; the size of each circle reflects the average annual sales per chain. Local SNAP prevalence refers to the average estimated share of the population that are SNAP recipients across the ZIP codes in which the grocery stores belonging to a chain are located. Log food expenditures are aggregated across products using weights derived from purchases by SNAP-eligible shoppers. Change in log sales refers to the estimated coefficient on SNAP Issuance Share, which is defined as the share of SNAP benefits issued during a given week of the month in the jurisdiction in which a store is located. The effect of SNAP issuance on log food expenditures is estimated from a specification that controls for store-year-month and year-month-week fixed effects, as well as the interaction of calendar week with log state population, log gross domestic product, and unemployment rate (corresponding to Column 3 in Table 1). The estimated slope of the best linear-fit is 0.013 , with standard error 0.002 . 


\title{
Figure A.2: Price Ratio Event-Study
}

\author{
(a) All Stores
}

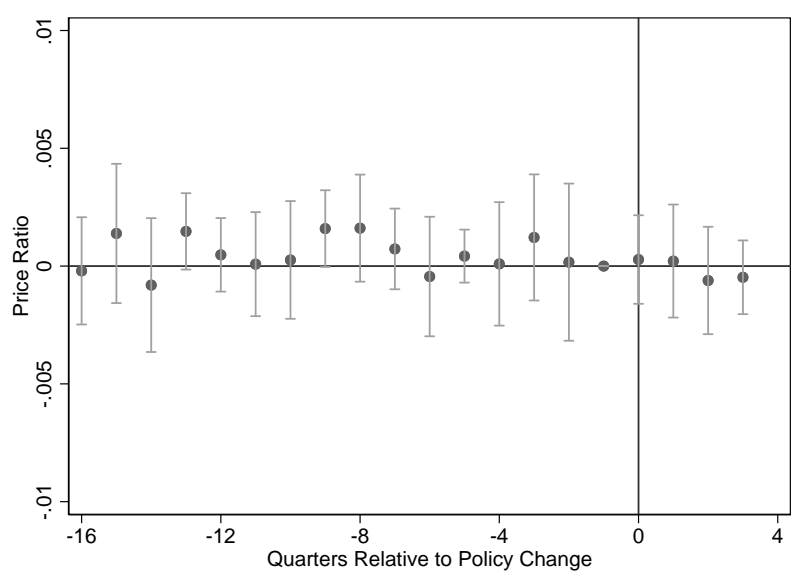

(b) High-SNAP Stores

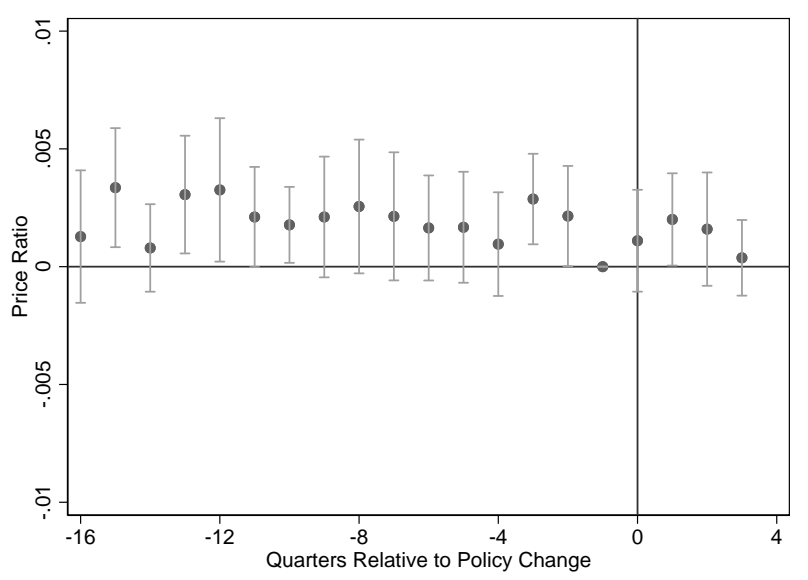

Notes: The figure displays the event-study analysis of the effect of policy reforms that staggered SNAP issuance on food prices. The outcome is the ratio of average log food prices in calendar weeks one and two to average log food prices across all four weeks of the month. Log food prices are aggregated across products using weights derived from purchases by SNAP-eligible shoppers. The estimates reflect the effect of policy reforms in the ten states that expanded the share of benefits issued during the third and fourth calendar weeks of the month during our sample period (see Appendix Table A.1). The analysis excludes the two states (Oklahoma and Virginia) that altered the share of SNAP benefits issued across calendar weeks during our sample period but that did not expand the share of benefits issued during the third and fourth calendar weeks of the month. The analysis also excludes Idaho, which reformed its issuance schedule during our sample period but did not alter the share of benefits issued across calendar weeks. The estimated effects are derived from a specification that controls for store-year-month and year-month-week fixed effects and that omits a coefficient for the effect of the intervention in the quarter prior to implementation (the reference period). Panel A contains all stores in the sample; Panel B is limited to stores for which we estimate that the share of SNAP recipients in the ZIP code is at least $20 \%$. The brackets surrounding the estimated effects reflect the $95 \%$ confidence interval from standard errors clustered by state. 
Figure A.3: Chain-Level Food Price Cyclicality by SNAP Prevalence

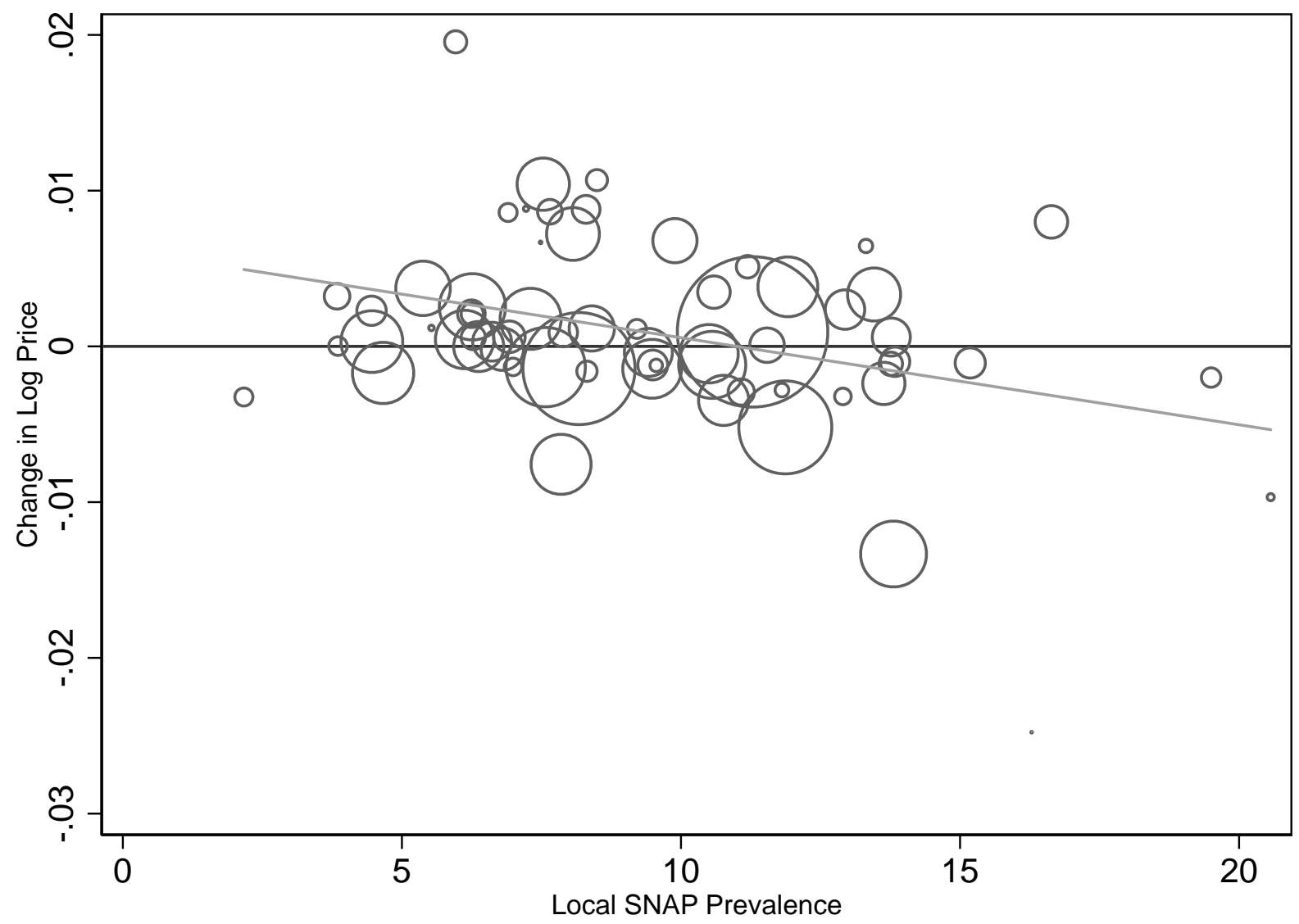

Notes: The figure displays the estimated effect of SNAP issuance on log prices by local SNAP prevalence at the grocery chain level. Each circle corresponds to one grocery store chain; the size of each circle reflects the average annual sales per chain. Local SNAP prevalence refers to the average estimated share of the population that are SNAP recipients across the ZIP codes in which the grocery stores belonging to a chain are located. Prices in a store-week correspond to an index of product-level log prices; the index uses weights derived from purchases by SNAP-eligible shoppers. Change in log prices refers to the estimated coefficient on SNAP Issuance Share, which is defined as the share of SNAP benefits issued during a given week of the month in the jurisdiction in which a store is located. The effect of SNAP issuance on log prices is estimated from a specification that controls for store-year-month and year-month-week fixed effects, as well as the interaction of calendar week with log state population, log gross domestic product, and unemployment rate (corresponding to Column 3 in Table 2). The estimated slope of the best linear-fit is -0.0004 , with standard error 0.0003 . 
Figure A.4: The Effect of SNAP Issuance on Elasticities versus Prices by Product

(a) All Stores

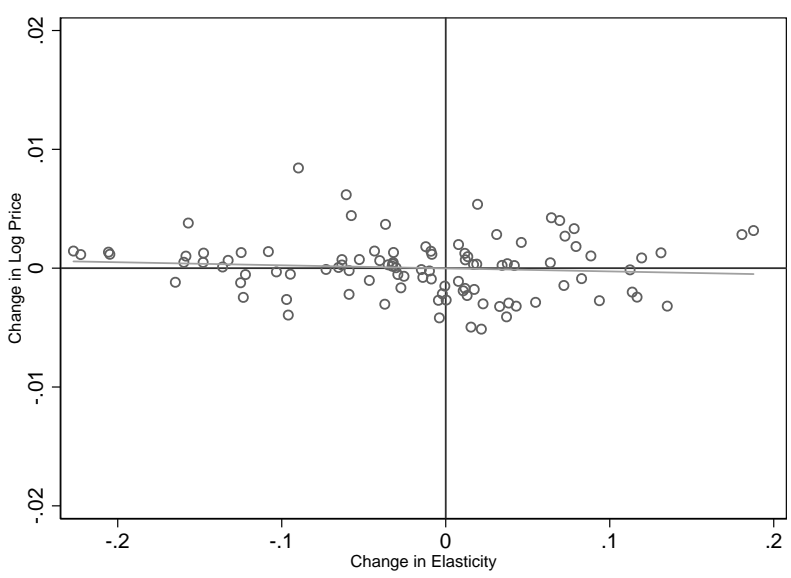

(b) High-SNAP Stores

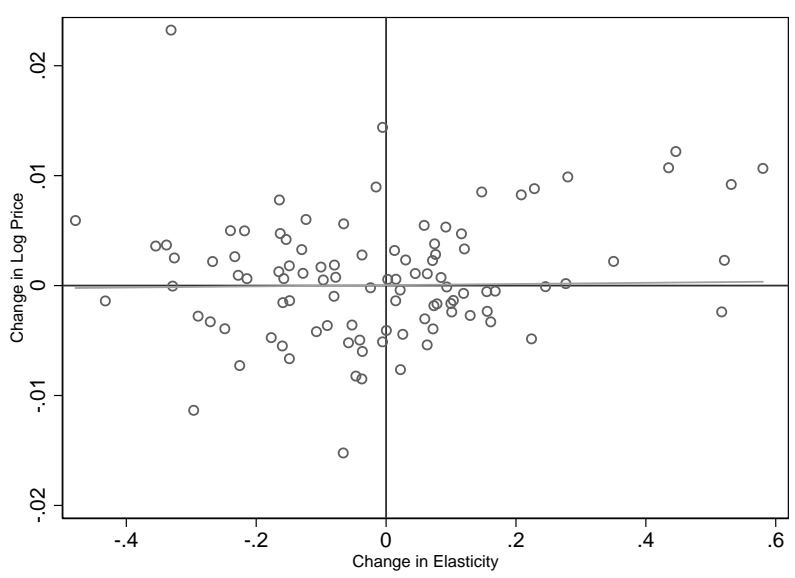

Notes: The figure plots the relationship between the effect of SNAP issuance on a product's price elasticity and the effect of SNAP issuance on the products price. Each point represents one of the top 100 food products by expenditure share among SNAP-eligible shoppers, subject to the limitation that the product was purchased in at least $80 \%$ of store-weeks. The x-axis represents the estimated effect of Issuance Share on a products price elasticity; it corresponds to the $\eta$ coefficient in (6). The y-axis represents the estimated effect of Issuance Share on the log of a products price during a given store-week. Issuance Share reflects the share of SNAP benefits issued during a given week of the month in the jurisdiction in which a store is located. Each estimate is obtained from a product-specific regression and controls for store-year-month and year-month-week fixed effects, as well as interactions of calendar week with state-year measures of log population, log GDP per capita, and unemployment rate. All estimates are obtained from specifications that are weighted by average annual store volume. Panel A contains all stores in the sample; Panel B is limited to stores for which we estimate that the share of SNAP recipients in the ZIP code is at least $20 \%$. The estimated slope of the best linear-fit is -0.0026 , with standard error 0.0028 in Panel A and 0.0046 with standard error 0.0026 in Panel B. 
Figure A.5: The Effect of SNAP Issuance on Elasticities versus Prices by Product Among One-Policy Chains

(a) All Stores

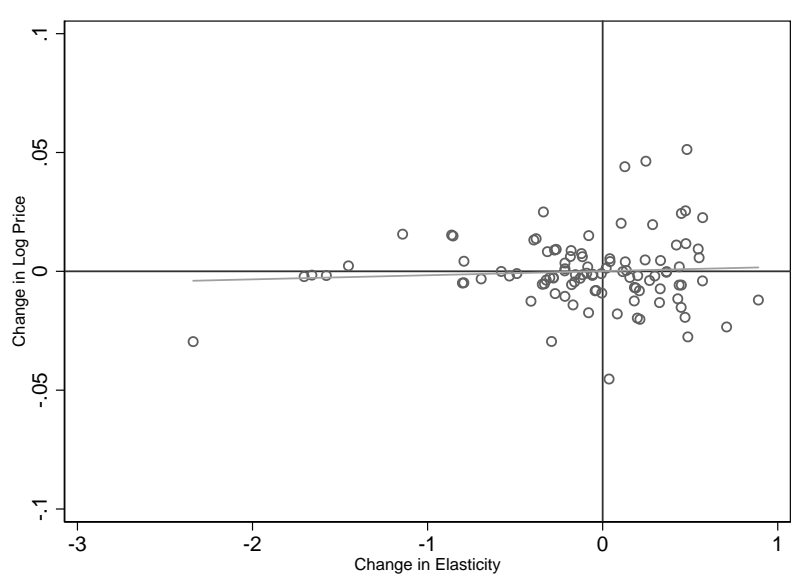

(b) High-SNAP Stores

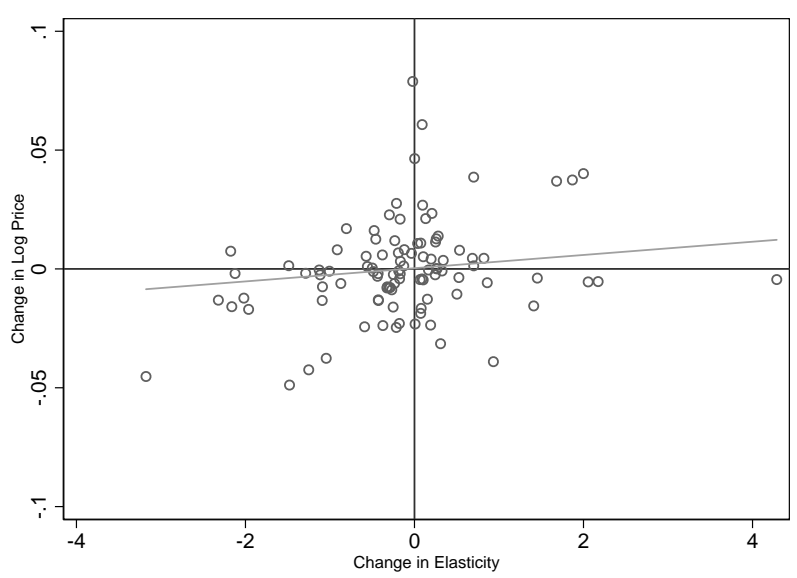

Notes: The figure plots the relationship between the effect of SNAP issuance on a product's price elasticity and the effect of SNAP issuance on the products price among chains facing a single SNAP issuance policy in each of their stores during a given week. Each point represents one of the top 100 food products by expenditure share among SNAP-eligible shoppers, subject to the limitation that the product was purchased in at least $80 \%$ of store-weeks. The x-axis represents the estimated effect of Issuance Share on a products price elasticity; it corresponds to the $\eta$ coefficient in (6). The y-axis represents the estimated effect of Issuance Share on the log of a products price during a given store-week. Issuance Share reflects the share of SNAP benefits issued during a given week of the month in the jurisdiction in which a store is located. Each estimate is obtained from a product-specific regression and controls for store-year-month and year-month-week fixed effects, as well as interactions of calendar week with state-year measures of log population, log GDP per capita, and unemployment rate. All estimates are obtained from specifications that are weighted by average annual store volume. Panel A contains all stores in the sample; Panel B is limited to stores for which we estimate that the share of SNAP recipients in the ZIP code is at least $20 \%$. The estimated slope of the best linear-fit is 0.0017 , with standard error 0.0027 in Panel A and 0.0057, with standard error 0.0019 in Panel B. 


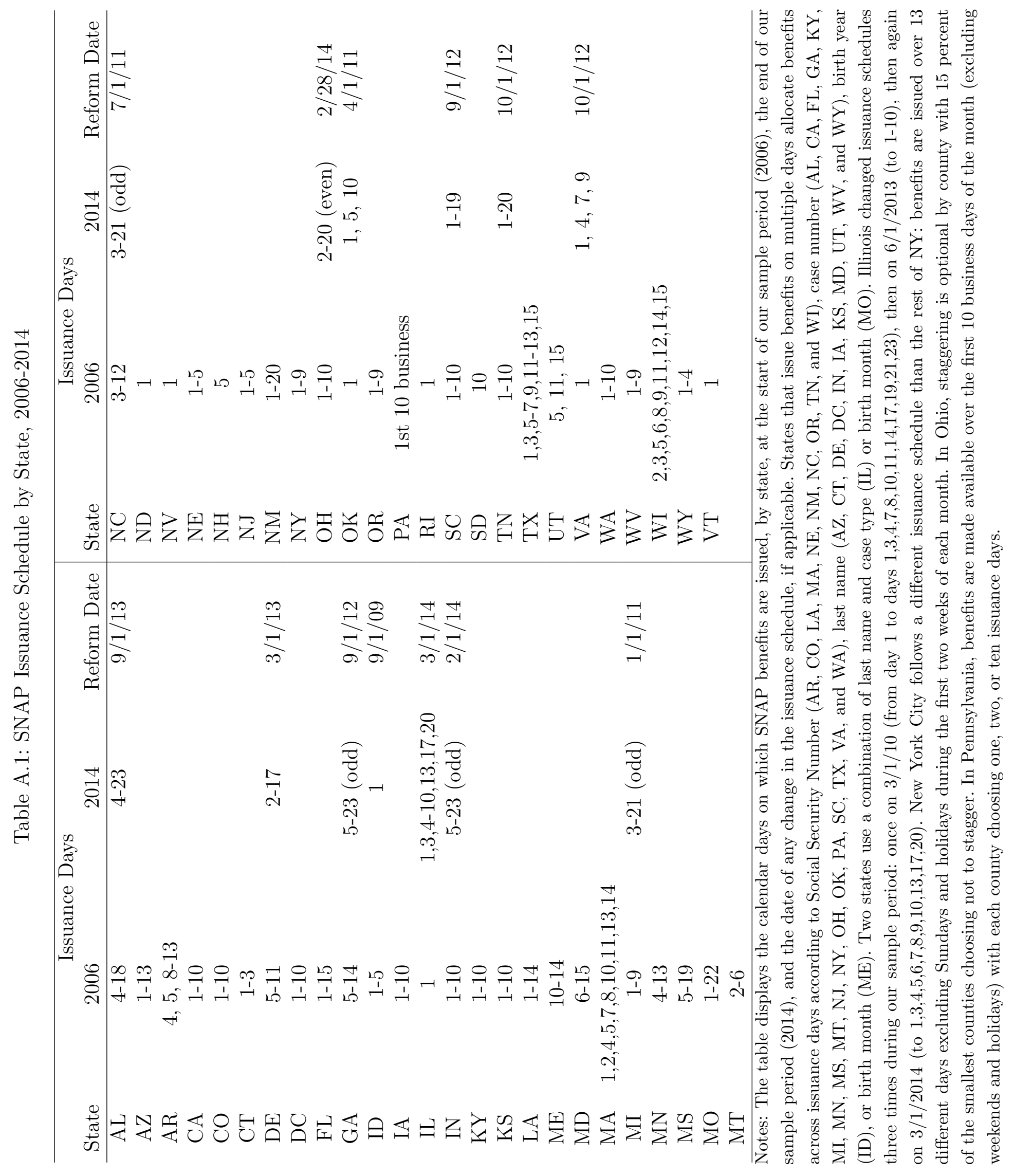




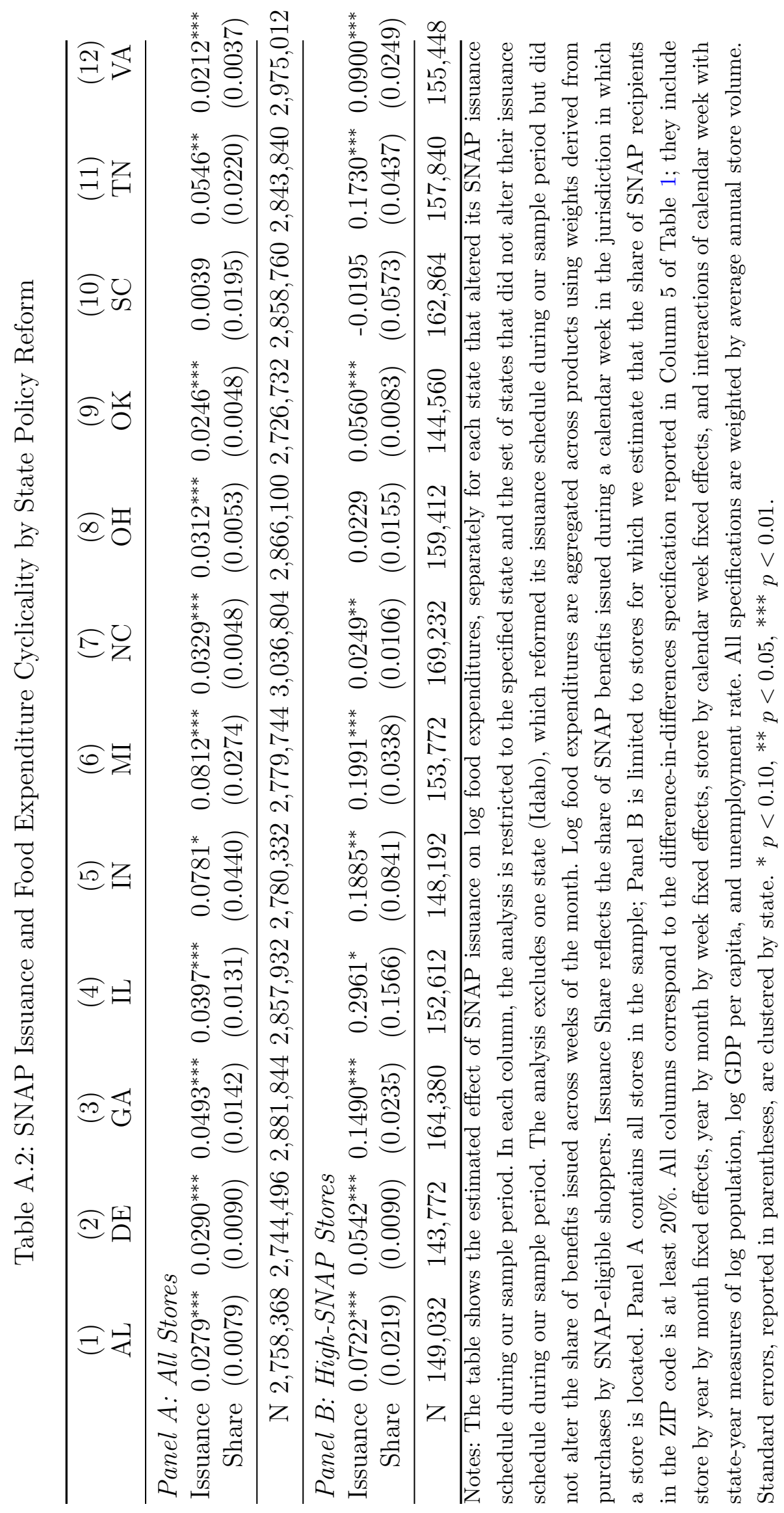




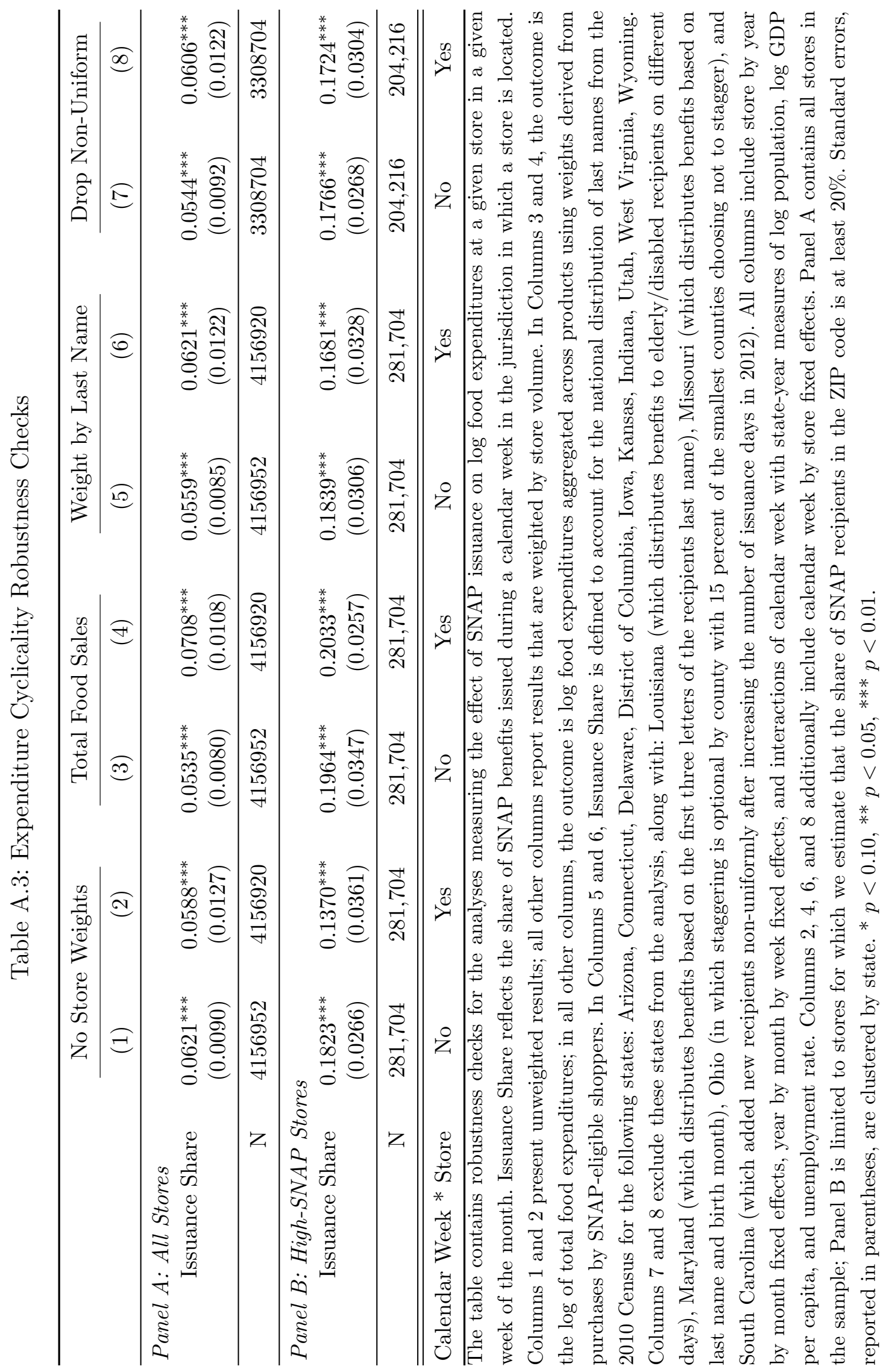


Table A.4: Food Expenditure Cyclicality by SNAP Issuance Policy

\begin{tabular}{|c|c|c|c|c|}
\hline & $\frac{\text { Week } 1}{(1)}$ & $\frac{\text { Week } 2}{(2)}$ & $\frac{\text { Weeks } 1 \& 2}{(3)}$ & $\frac{\text { Weeks 1-3+ }}{(4)}$ \\
\hline \multicolumn{5}{|c|}{ Panel A: All Stores } \\
\hline Week 2 & $\begin{array}{c}-0.0619^{* * *} \\
(0.0063)\end{array}$ & $\begin{array}{c}0.0151 \\
(0.0265)\end{array}$ & $\begin{array}{c}-0.0293^{* * *} \\
(0.0060)\end{array}$ & $\begin{array}{c}-0.0300^{*} \\
(0.0151)\end{array}$ \\
\hline Week 3 & $\begin{array}{c}-0.0654^{* * *} \\
(0.0081)\end{array}$ & $\begin{array}{c}0.0215 \\
(0.0241)\end{array}$ & $\begin{array}{c}-0.0416^{* * *} \\
(0.0079)\end{array}$ & $\begin{array}{l}-0.0205 \\
(0.0199)\end{array}$ \\
\hline Week 4 & $\begin{array}{c}-0.0306^{* *} \\
(0.0112)\end{array}$ & $\begin{array}{c}0.0072 \\
(0.0111)\end{array}$ & $\begin{array}{c}-0.0278^{* * *} \\
(0.0067)\end{array}$ & $\begin{array}{l}-0.0039 \\
(0.0101)\end{array}$ \\
\hline $\mathrm{N}$ & 565,470 & 55,834 & $3,105,655$ & 430,127 \\
\hline \multicolumn{5}{|c|}{ Panel B: High-SNAP Stores } \\
\hline Week 2 & $\begin{array}{c}-0.1528^{* * *} \\
(0.0395)\end{array}$ & $\begin{array}{c}0.0860^{* *} \\
(0.0060)\end{array}$ & $\begin{array}{c}-0.0093 \\
(0.0216)\end{array}$ & $\begin{array}{c}0.0056 \\
(0.0254)\end{array}$ \\
\hline Week 3 & $\begin{array}{c}-0.2184^{* * *} \\
(0.0241)\end{array}$ & $\begin{array}{c}0.0666 \\
(0.0118)\end{array}$ & $\begin{array}{c}-0.0975^{* * *} \\
(0.0285)\end{array}$ & $\begin{array}{c}-0.0251 \\
(0.0431)\end{array}$ \\
\hline Week 4 & $\begin{array}{c}-0.1905^{* * *} \\
(0.0073)\end{array}$ & $\begin{array}{c}0.0077 \\
(0.0069)\end{array}$ & $\begin{array}{c}-0.1306^{* * *} \\
(0.0221)\end{array}$ & $\begin{array}{l}-0.0648^{*} \\
(0.0329)\end{array}$ \\
\hline $\mathrm{N}$ & 16,933 & 3,845 & 219,262 & 41,699 \\
\hline
\end{tabular}

Notes: The table shows within-month expenditure patterns by state SNAP issuance policy. Log food expenditures are aggregated across products using weights derived from purchases by SNAP-eligible shoppers. Column 1 includes stores located in states that issue all benefits during the first week of the month. Column 2 includes stores located in states that issue all benefits during the second week of the month. Column 3 includes stores located in states that issue benefits on days spanning the first two weeks of the month. Column 4 includes stores located in states that issue benefits on days spanning three or more weeks during the month. Stores located in states that switch policies during our sample period are classified according to the policy that is in place during a given store-month. Panel A contains all stores in the sample; Panel B is limited to stores for which we estimate that the share of SNAP recipients in the ZIP code is at least $20 \%$. All columns include store by year by month fixed effects. All specifications are weighted by average annual store volume. Standard errors, reported in parentheses, are clustered by state. ${ }^{*} p<0.10,{ }^{* *} p<0.05,{ }^{* * *}$ $p<0.01$. 
Table A.5: The Effect of SNAP Issuance on Non-Food Expenditure Cyclicality

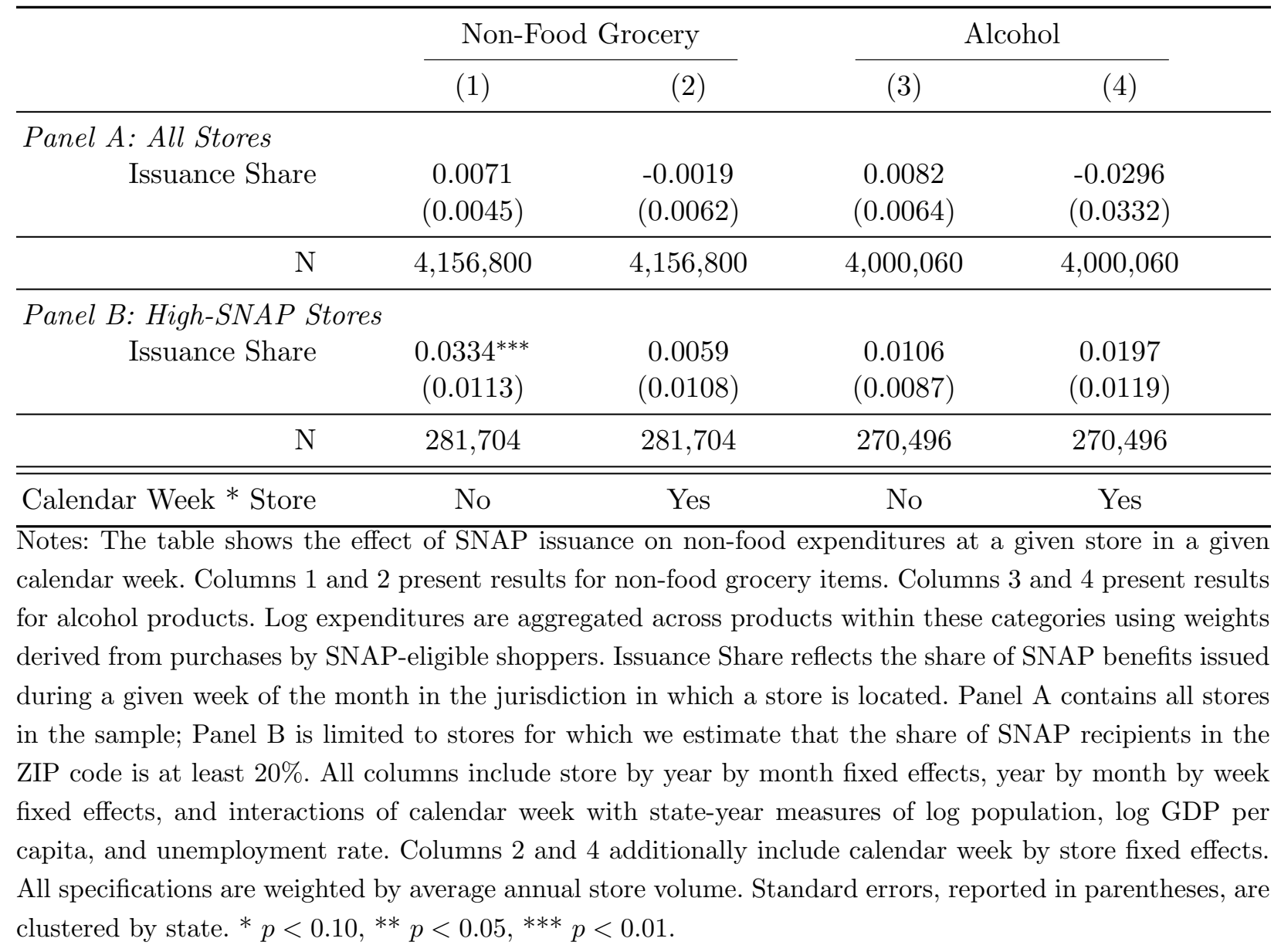




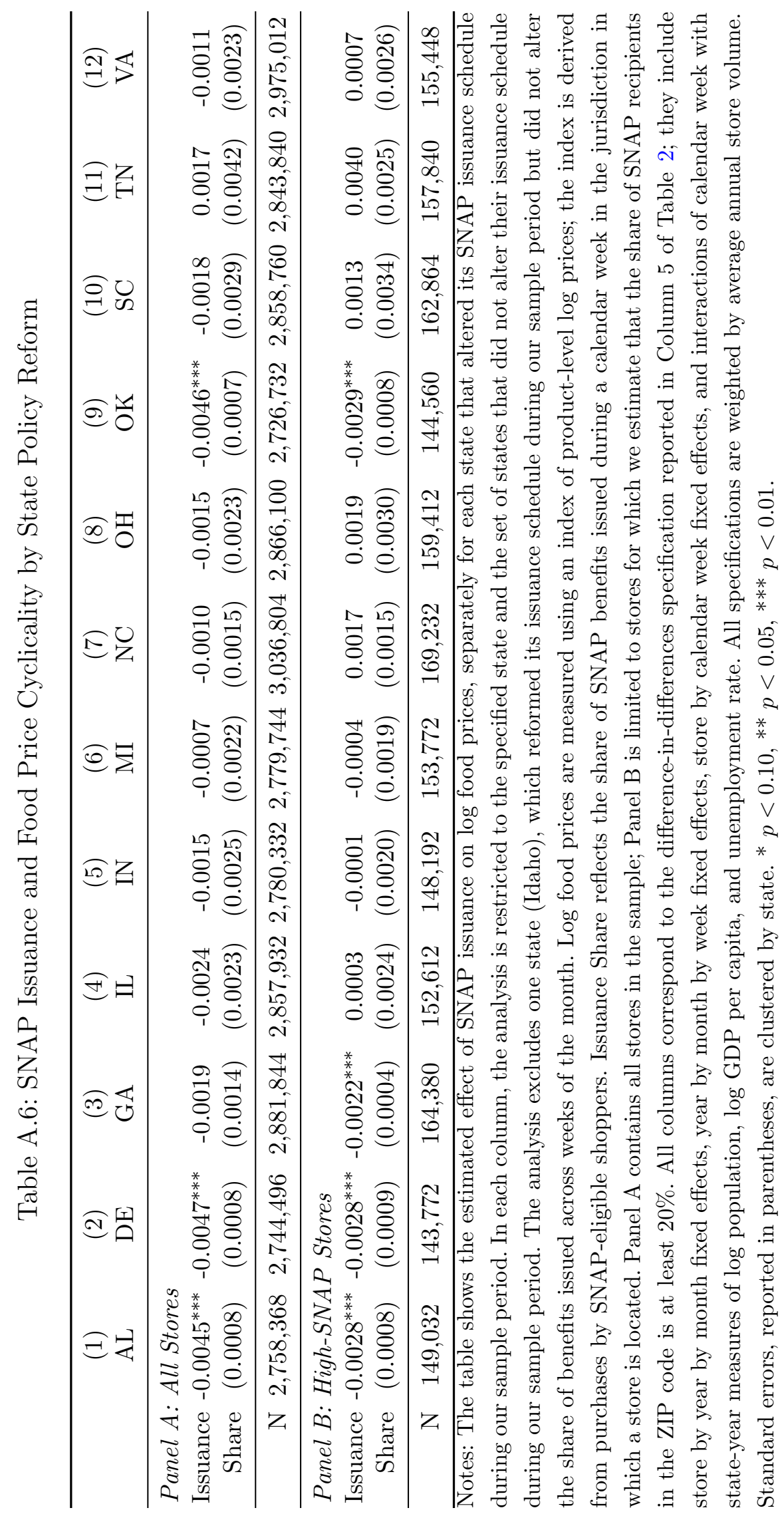




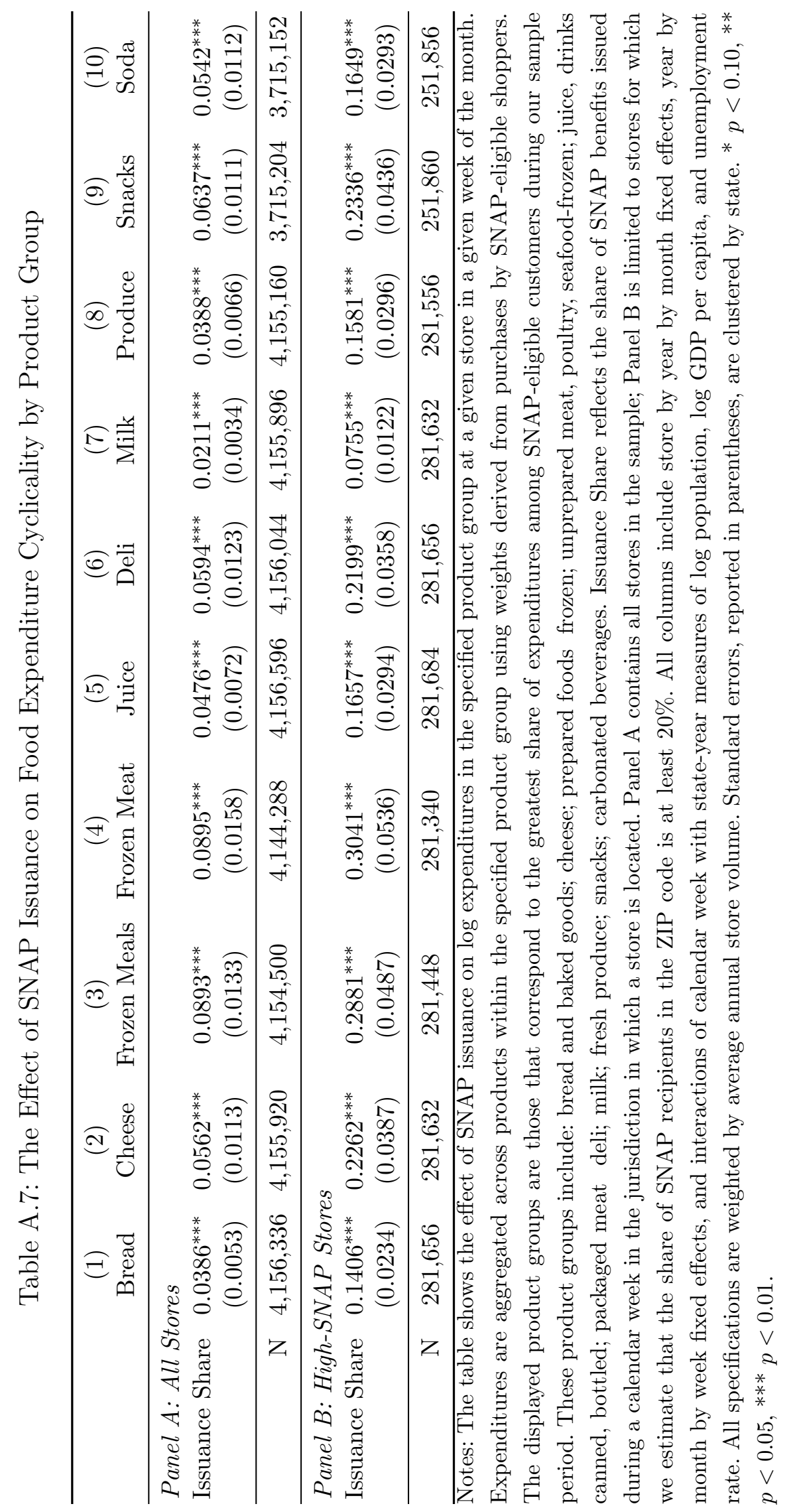




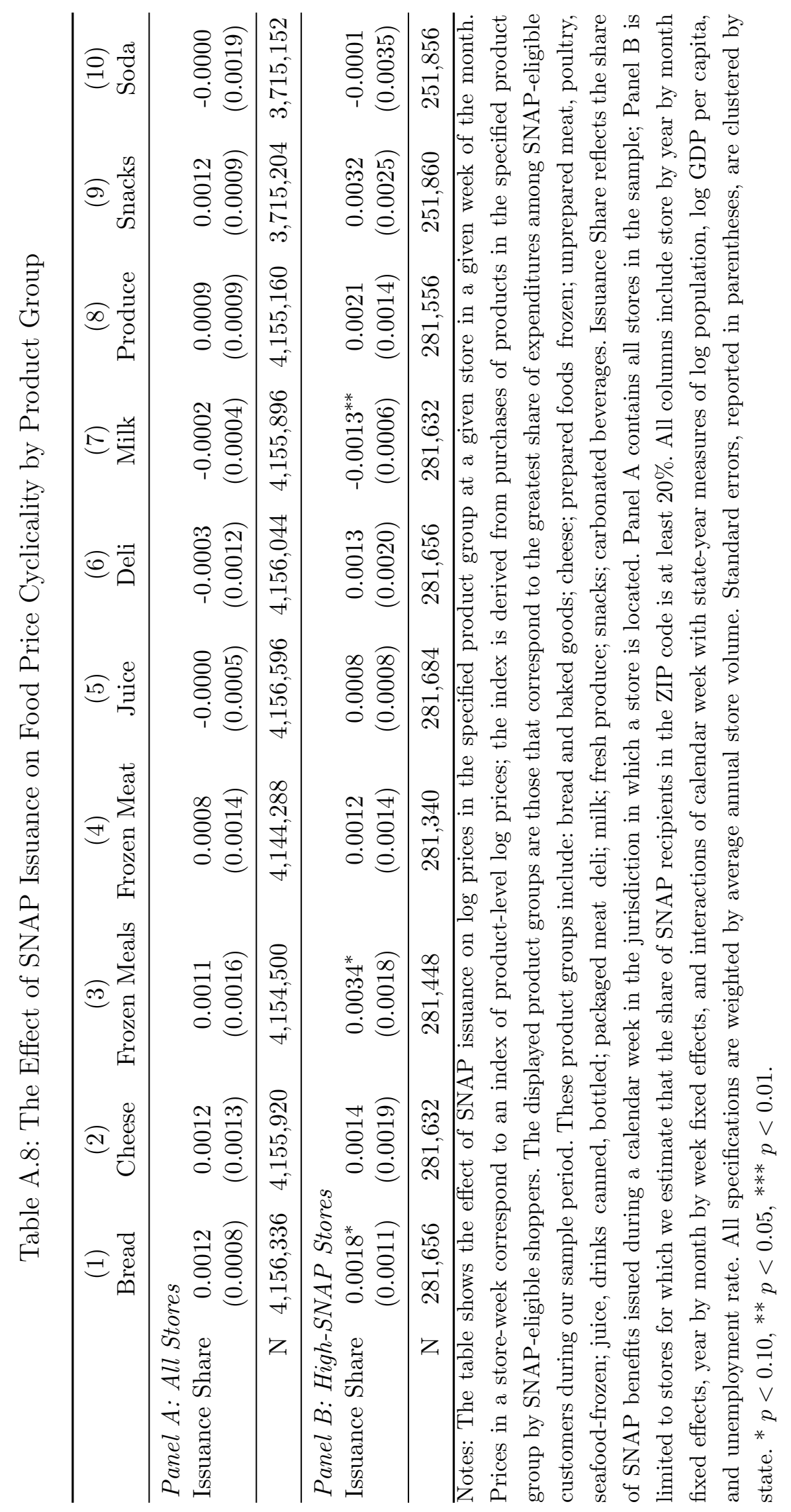


Table A.9: Effect of SNAP Issuance on Expenditure and Price Cyclicality, High SNAP-Share Product Modules

\begin{tabular}{cccccc}
\hline & \multicolumn{2}{c}{ Sales } & & \multicolumn{2}{c}{ Price } \\
\cline { 2 - 3 } \cline { 5 - 6 } & $(1)$ & $(2)$ & & $(3)$ & $(4)$ \\
\hline Panel A: All Stores & & & & \\
Issuance Share & $0.0618^{* * *}$ & $0.0581^{* * *}$ & & -0.0008 & 0.0016 \\
& $(0.0110)$ & $(0.0209)$ & $(0.0010)$ & $(0.0029)$ \\
\hline $\mathrm{N}$ & $4,156,820$ & $4,156,820$ & $4,156,820$ & $4,156,820$ \\
\hline Panel B: High-SNAP Stores & & & & \\
Issuance Share & $0.1806^{* * *}$ & $0.1565^{* * *}$ & & -0.0008 & 0.0022 \\
& $(0.0285)$ & $(0.0532)$ & $(0.0018)$ & $(0.0040)$ \\
\hline \hline N & 281,704 & 281,704 & 281,704 & 281,704 \\
\hline \hline Calendar Week * Store & No & Yes & No & Yes \\
\hline
\end{tabular}

Notes: The table shows the effect of SNAP issuance on sales and prices for food products corresponding to modules that tend to be purchased by SNAP-eligible customers at a high rate relative to SNAP-ineligible customers. To select these modules, using the Consumer Panel we estimate, for each module, the share of all food expenditures that the module represents, separately for SNAP-eligible and ineligible customers. The sample underlying the analysis in the table corresponds to the products in the ten modules with the largest ratio of these two shares. These modules are: frozen/refrigerated appetizers and snacks, carbonated soft drinks, mayonnaise, certain fruit drinks, certain fruit juices, toaster pastries, frozen Mexican entrees, salad and cooking oil, yogurt, and cottage cheese. Log food expenditures (columns 1 and 2) are aggregated across products using weights derived from purchases by SNAP-eligible shoppers. Log food prices (columns 3 and 4) correspond to an index of product-level log prices derived from purchases by SNAP-eligible shoppers. Issuance Share reflects the share of SNAP benefits issued during a calendar week in the jurisdiction in which a store is located. Panel A contains all stores in the sample; Panel B is limited to stores for which we estimate that the share of SNAP recipients in the ZIP code is at least 20\%. All columns include store by year by month fixed effects, year by month by week fixed effects, and interactions of calendar week with state-year measures of log population, log GDP per capita, and unemployment rate. Columns 2 and 4 additionally include calendar week by store fixed effects. All specifications are weighted by average annual store volume. Standard errors, reported in parentheses, are clustered by state. ${ }^{*} p<0.10,{ }^{* *} p<0.05,{ }^{* * *} p<0.01$. 
Table A.10: Price Cyclicality Robustness Checks

\begin{tabular}{|c|c|c|c|c|c|c|}
\hline & \multicolumn{2}{|c|}{ No Store Weights } & \multicolumn{2}{|r|}{ Last Name } & \multicolumn{2}{|c|}{ Drop Non-Uniform } \\
\hline & (1) & (2) & (3) & (1) & (5) & $(6)$ \\
\hline \multicolumn{7}{|l|}{ Panel A: All Stores } \\
\hline Issuc & & $\begin{array}{c}0.0011 \\
(0.0008)\end{array}$ & & & & \\
\hline $\mathrm{N}$ & 4156952 & 4156952 & 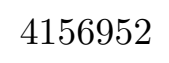 & 52 & 3308 & 330 \\
\hline \multicolumn{7}{|c|}{ Panel B: High-SNAP Stores } \\
\hline & & & & & $\begin{array}{c}0.0003 \\
(0.0007)\end{array}$ & $\begin{array}{c}0.0004 \\
(0.0014)\end{array}$ \\
\hline $\mathrm{N}$ & 281,704 & 281,704 & 281,704 & 281,704 & 204,216 & 204,204 \\
\hline Calendar Week $*$ Store & No & Yes & $\mathrm{No}$ & Yes & $\mathrm{No}$ & Yes \\
\hline \multicolumn{7}{|c|}{ 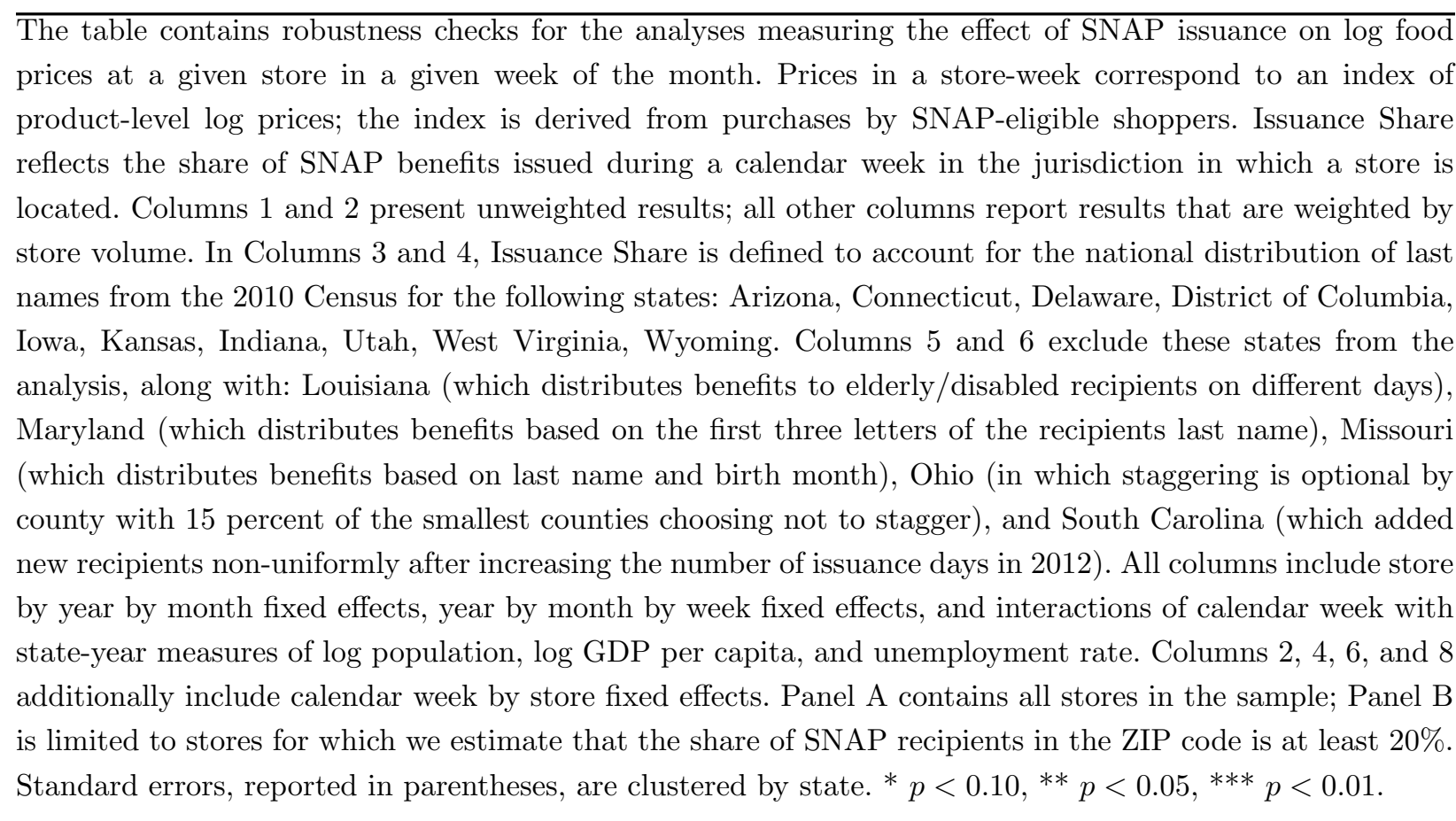 } \\
\hline
\end{tabular}




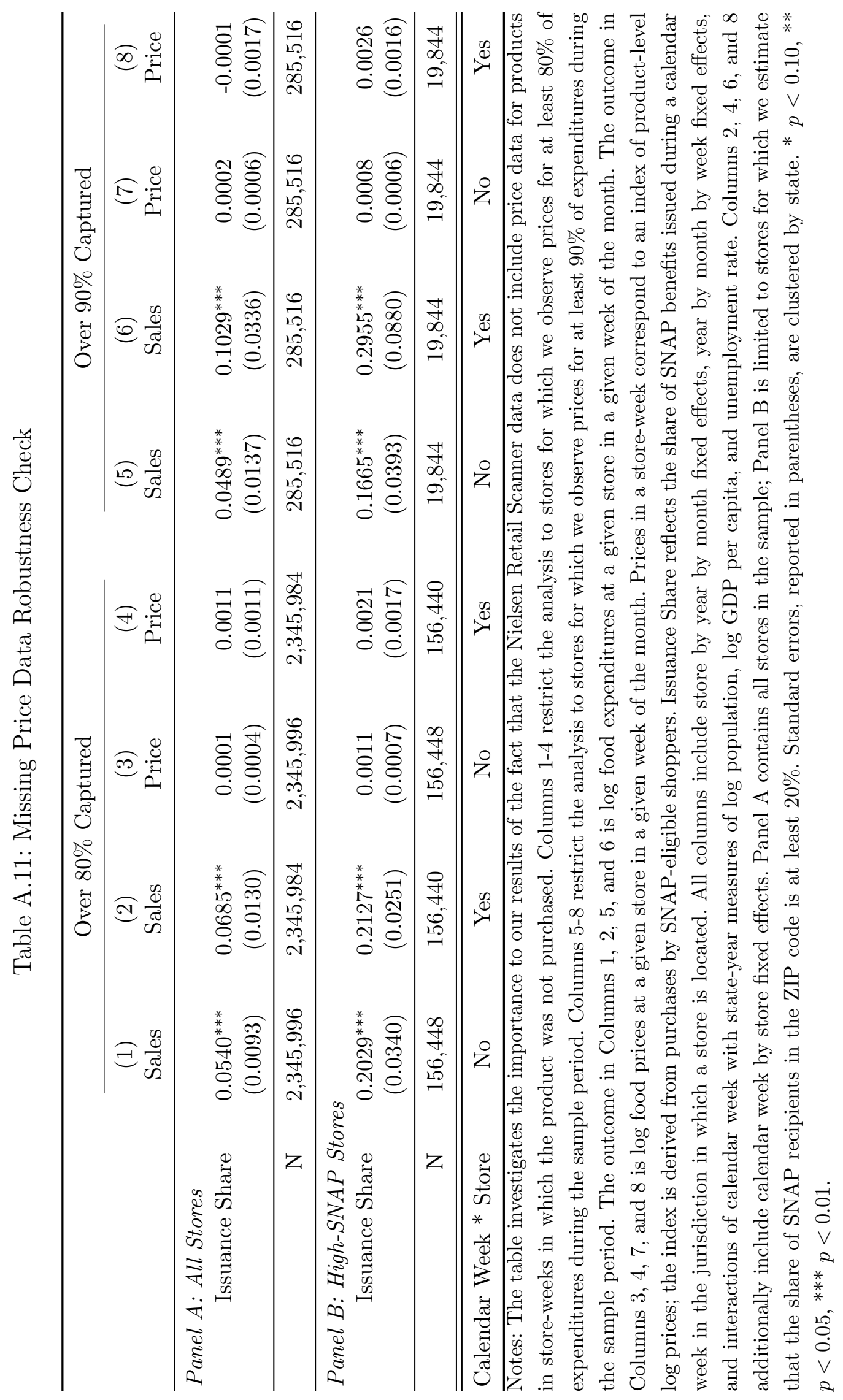


Table A.12: The Effect of SNAP Issuance on Coupon Usage and Discount Receipt

\begin{tabular}{cccccc}
\hline & \multicolumn{2}{c}{ Coupon Use } & & \multicolumn{2}{c}{ Discount Receipt } \\
\cline { 2 - 3 } & $(1)$ & $(2)$ & & $(3)$ & $(4)$ \\
\hline Panel A: All Stores & & & & \\
Issuance Share & 0.0001 & -0.0009 & & 0.0012 & -0.0022 \\
& $(0.0003)$ & $(0.0008)$ & & $0.0009)$ & $(0.0033)$ \\
\hline $\mathrm{N}$ & $2,434,518$ & $2,434,518$ & $2,434,518$ & $2,434,518$ \\
Mean, Dep. Var. & 0.0448 & 0.0448 & 0.4227 & 0.4227 \\
\hline Panel B: High-SNAP Stores & & & & \\
Issuance Share & -0.0018 & 0.0003 & & -0.0049 & 0.0125 \\
& $(0.0014)$ & $(0.0035)$ & & $0.0064)$ & $(0.0097)$ \\
\hline N & 146,638 & 146,638 & & 146,638 & 146,638 \\
Dep Var Mean & 0.0389 & 0.0389 & & 0.3920 & 0.3920 \\
\hline \hline Calendar Week * Store & No & Yes & No & Yes \\
\hline
\end{tabular}

Notes: The table shows the effect of SNAP issuance on coupon use and discount receipt in a given store in a given week of the month using data from the Consumer Panel. Columns 1 and 2 present results for the effect of SNAP issuance on the average value of coupons as a share of expenditures per shopping trip. Columns 3 and 4 present results for the effect of SNAP issuance on the average share per shopping trip of expenditures on items for which the panelist reported receiving a discounted price deal. Both outcomes use panelist weights to calculate the average across trips. Issuance Share reflects the share of SNAP benefits issued during a given week of the month in the jurisdiction in which a store is located. Panel A contains shopping trips at all stores in the sample; Panel B is limited to shopping trips at stores for which we estimate that the share of SNAP recipients in the ZIP code is at least 20\%. All columns include store by year by month fixed effects, year by month by week fixed effects, and interactions of calendar week with state-year measures of $\log$ population, $\log$ GDP per capita, and unemployment rate. Columns 2 and 4 additionally include calendar week by store fixed effects. All specifications are weighted by average annual store volume. Standard errors, reported in parentheses, are clustered by state. ${ }^{*} p<0.10,{ }^{* *} p<0.05,{ }^{* * *} p<0.01$. 
Table A.13: The Effect of SNAP Issuance on Non-Food Price Cyclicality

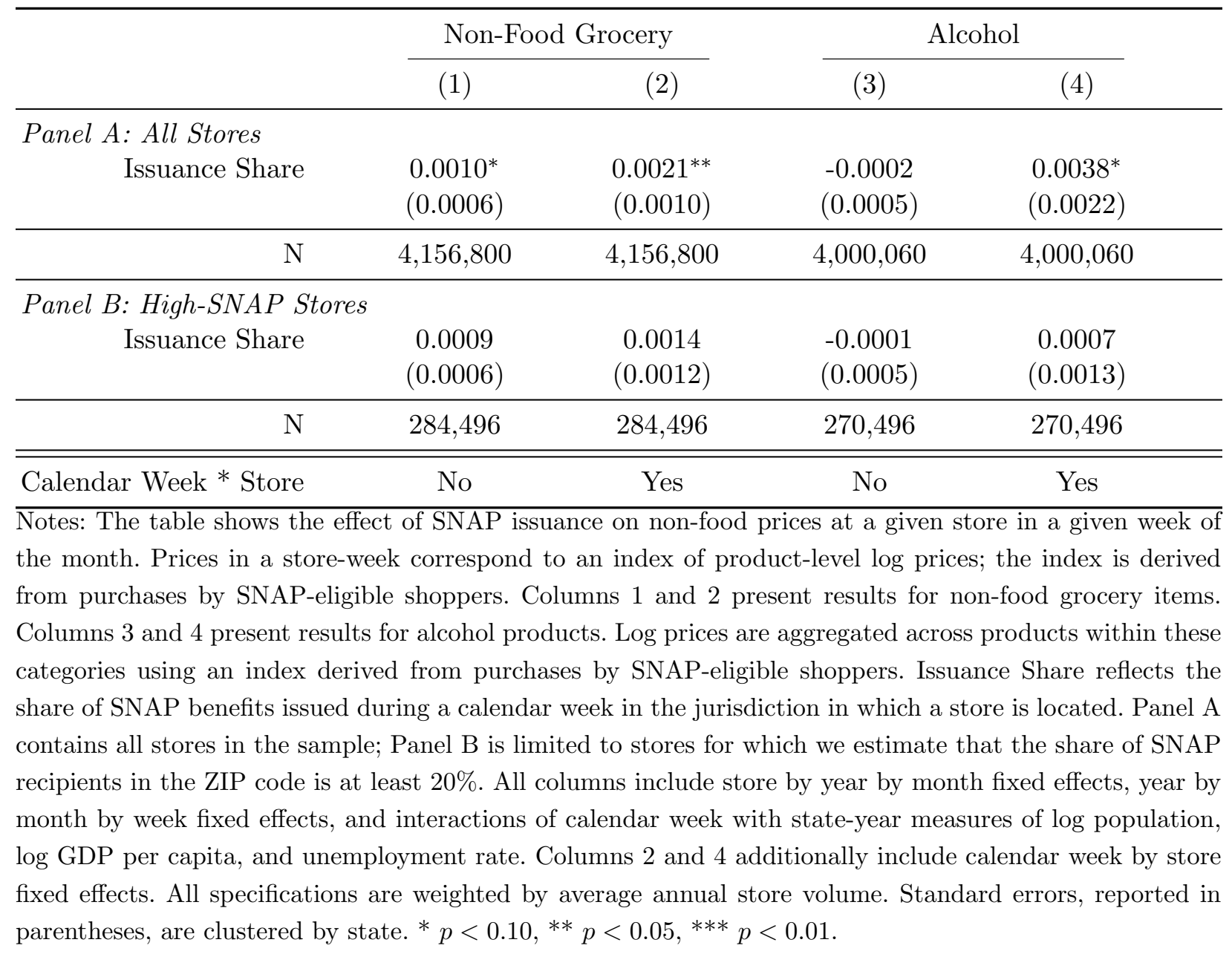


Table A.14: The Effect of SNAP Issuance on Sales and Prices, 100 Product Sample

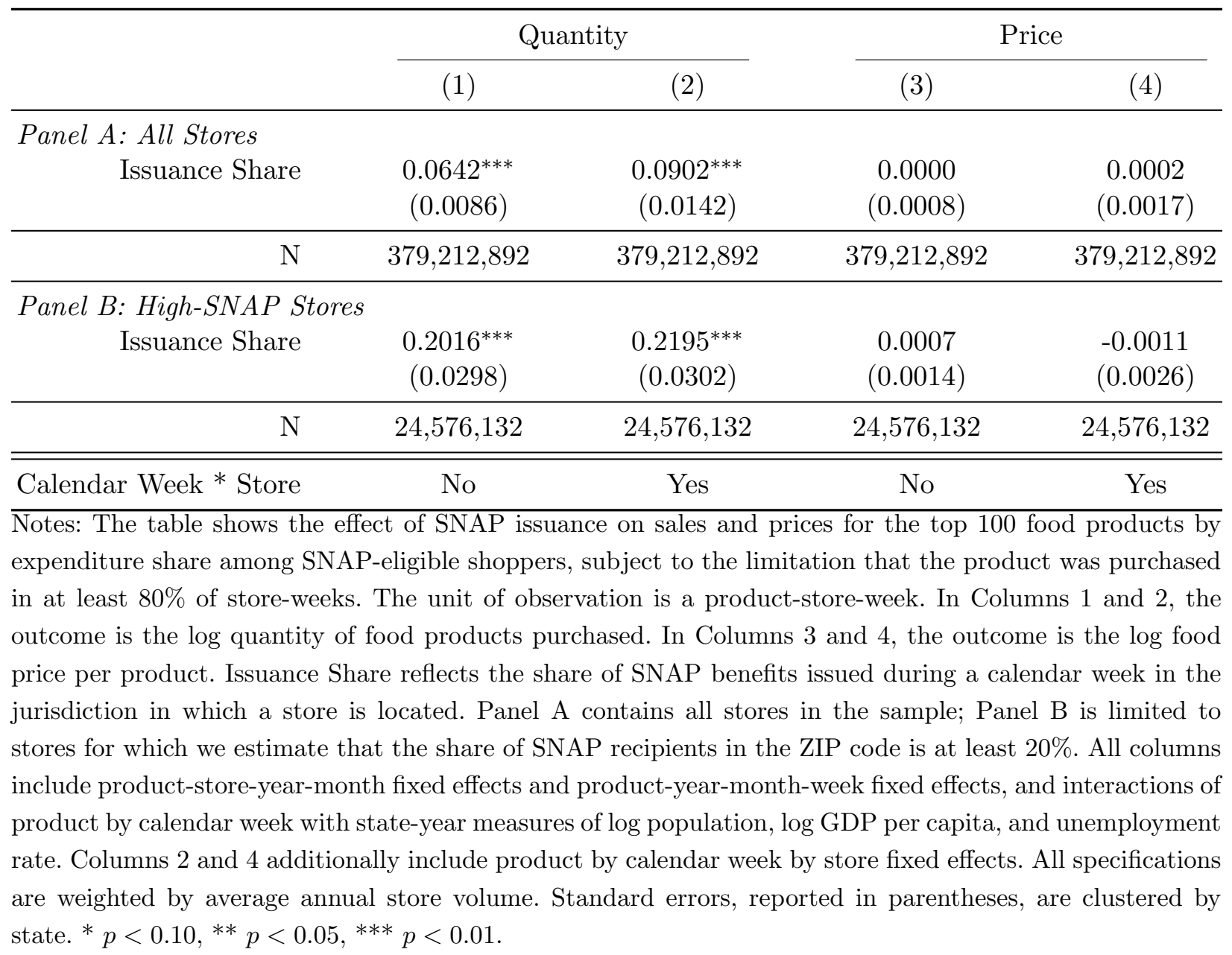


Table A.15: Price Imputation Robustness Check

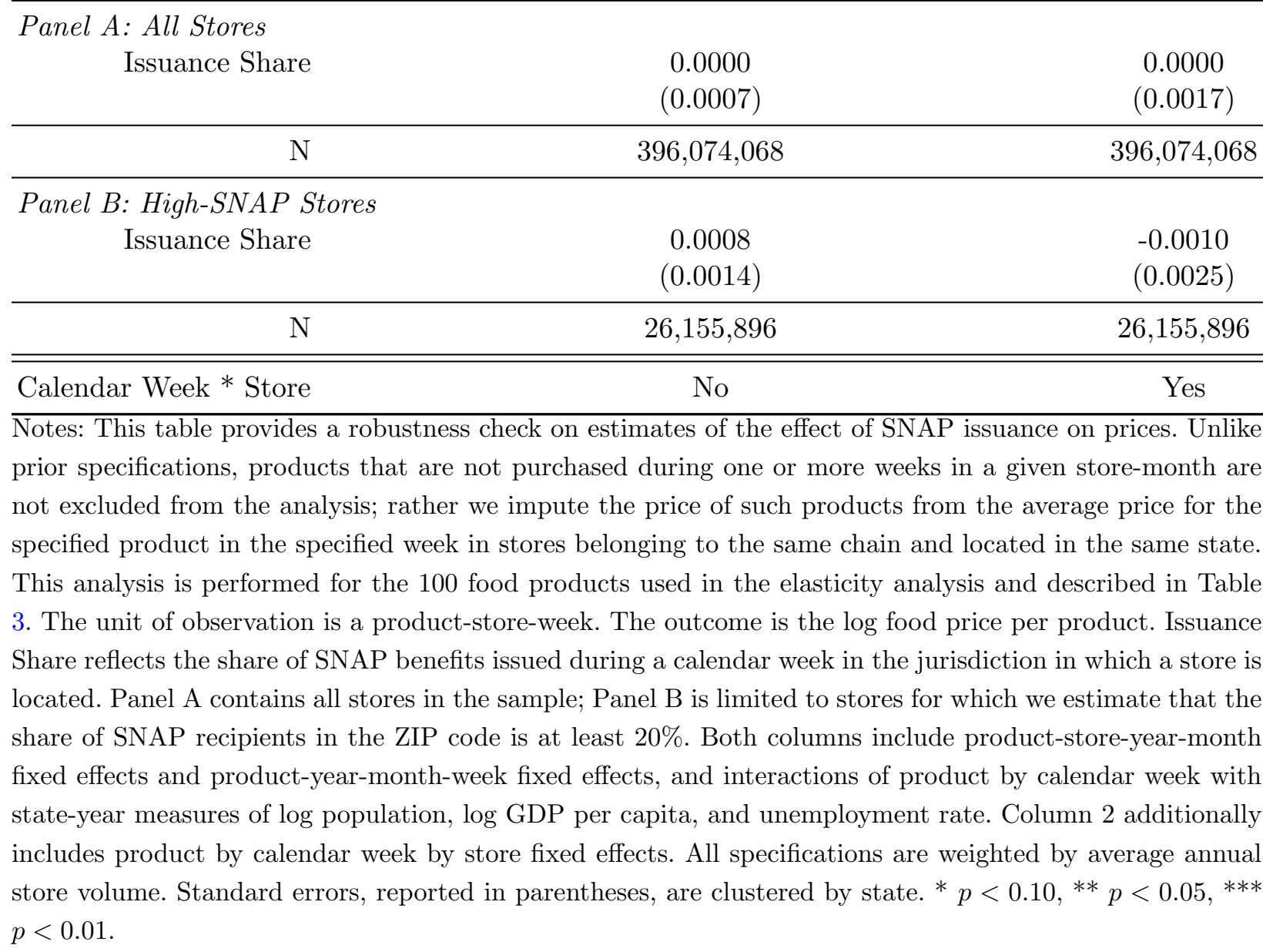


Table A.16: First Stage Effect of DMA Price Instrument on Product Price

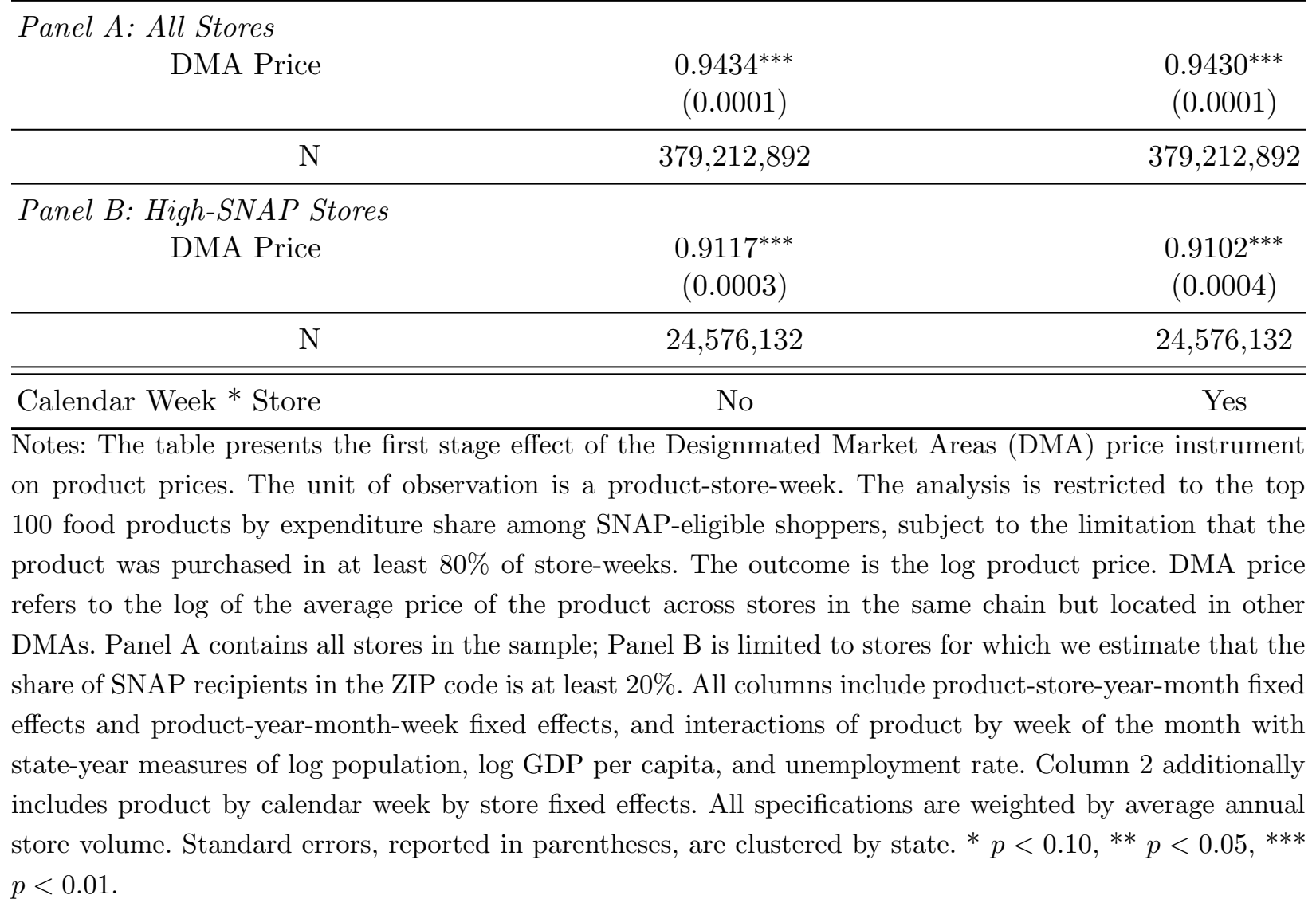

